\title{
Monocyte infiltration rather than microglia proliferation dominates the early immune response to rapid photoreceptor degeneration
}

\author{
Sarah J. Karlen ${ }^{1}$, Eric B. Miller ${ }^{2}$, Xinlei Wang ${ }^{1,3}$, Emily S. Levine ${ }^{1}$, Robert J. Zawadzki ${ }^{3}$ and Marie E. Burns ${ }^{1,2,3^{*}}$
}

\begin{abstract}
Background: Activation of resident microglia accompanies every known form of neurodegeneration, but the involvement of peripheral monocytes that extravasate and rapidly transform into microglia-like macrophages within the central nervous system during degeneration is far less clear.

Methods: Using a combination of in vivo ocular imaging, flow cytometry, and immunohistochemistry, we investigated the response of infiltrating cells in a light-inducible mouse model of photoreceptor degeneration.

Results: Within $24 \mathrm{~h}$, resident microglia became activated and began migrating to the site of degeneration. Retinal expression of CCL2 increased just prior to a transient period of $\mathrm{CCR}^{+}$cell extravasation from the retinal vasculature. Proliferation of microglia and monocytes occurred concurrently; however, there was no indication of proliferation in either population until 72-96 h after neurodegeneration began. Eliminating CCL2-CCR2 signaling blocked monocyte recruitment, but did not alter the extent of retinal degeneration.

Conclusions: These results demonstrate that the immune response to photoreceptor degeneration includes both resident microglia and monocytes, even at very early times. Surprisingly, preventing monocyte infiltration did not block neurodegeneration, suggesting that in this model, degeneration is limited by cell clearance from other phagocytes or by the timing of intrinsic cell death programs. These results show monocyte involvement is not limited to disease states that overwhelm or deplete the resident microglial population and that interventions focused on modulating the peripheral immune system are not universally beneficial for staving off degeneration.
\end{abstract}

Keywords: Neuroinflammation, Retina, Macrophage, Monocyte, Myeloid cells, Microglia, Photoreceptor, Rod, Cone

\section{Key points}

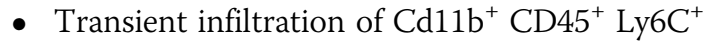
$\mathrm{CCR} 2^{+}$monocytes from retinal vessels occurs within $24 \mathrm{~h}$ of the onset of photoreceptor stress.

- Monocyte recruitment is preceded by increased retinal CCL2 expression.
- Blocking the CCL2-CCR2 signaling pathway prevents monocyte recruitment, but does not alter the overall rate of degeneration.

- Both microglia and monocyte proliferation occur concurrently, but not until several days after the onset of neurodegeneration, when the rate of cell death has slowed.

\footnotetext{
* Correspondence: meburns@ucdavis.edu

'Department of Cell Biology and Human Anatomy, University of California,

Davis, 1 Shields Avenue, Davis, CA 95616, USA

${ }^{2}$ Center for Neuroscience, University of California, Davis, 1544 Newton Court,

Davis, CA 95618, USA

Full list of author information is available at the end of the article
}

\section{Background}

Microglia are the resident immune cells of the central nervous system [1-5]. In healthy retina, microglia are confined to the synaptic and ganglion cell layers, where they survey their surrounding environment with dynamic ramifications to maintain tissue homeostasis and normal 
synaptic function [6]. During neurodegeneration, local changes in chemokines, purines, and the ionic milieu cause microglia to lose their ramifications and become amoeboid, a cellular state capable of rapid migration and greater phagocytic capacity [7]. Bone marrow-derived monocytes can also be recruited from the systemic circulation to further escalate the inflammatory response, often when the microglia population becomes depleted ([8] for review). Because infiltrating monocytes differentiate into macrophages that become difficult to distinguish from resident immune cells [9], determining the roles of these populations in the progression of degeneration has been difficult.

One method commonly used to separate resident microglia from infiltrating monocytes has been bone marrow transplant studies $[9,10]$. A drawback to this method is that the radiation that kills myeloid cells can kill microglia as well, leading to the establishment of non-microglia macrophages in the retina that out-populate bona fide microglia and obscure the natural dynamics during neurodegeneration $[11,12]$. A second approach has been to deplete circulating monocytes with clodronate liposomes, which in some models delays degeneration [13, 14], suggesting that infiltrating cells are primarily harmful. However, because the characteristics of both resident and infiltrating cells can change over time, a deeper understanding of their respective roles requires disambiguating their molecular phenotypes and correlating individual phenotypes with cellular behaviors during the onset and progression of neurodegenerative disease ([15-17] for review).

The Arrestin-1 knockout mouse ( $\left.\mathrm{Arrl}^{-/-} \mathrm{aka} \mathrm{Sag}^{-1-}\right)$ [18] allows the natural immune response to cell-autonomous neurodegeneration to be readily controlled and studied over time. Arrestin-1, also known as S-antigen or visual arrestin, is only expressed in rod and cone photoreceptors where it is responsible for quenching the activity of light-activated rhodopsin in the phototransduction cascade [19]. In mice lacking Arrestin-1, phototransduction signaling in retinal rods is greatly prolonged and results in light-induced photoreceptor degeneration from within an otherwise fully developed, normal retina [18, 20-23]. As a result, exposing dark-reared animals to normal lab lighting $(25-200 \mathrm{~lx})$ induces widespread microglial activation and a dramatic increase in $\mathrm{Iba}^{+}$cell numbers in the retinas of $\mathrm{Arrl}^{-/-}$mice [24]. Since Iba1 is expressed in both microglia and macrophages, this observation led us to examine whether the increase in $\mathrm{Iba}^{+}$cell number is primarily due to microglial proliferation or to monocyte infiltration in order to assess the roles that these populations play during degeneration.

Since Arrestin-1 is only expressed in rod and cone photoreceptors, it is an ideal model for studying the inflammatory response to single cell-specific degeneration within the central nervous system. Unlike models where the experimental manipulation itself can contribute to an immune response, the effects measured in this model are caused directly by the degeneration of a single neuronal cell type. Thus, the conclusions reached can be extrapolated to models of disease that are also due to neuron-specific degeneration. In the eye, these types of diseases often fall under the broad category of hereditary retinopathy (e.g., retinitis pigmentosa), which can affect photoreceptors or retinal pigment epithelium cells and represents a significant cause of blindness in humans ([25] for review).

Here, we show that in the $A r r 1^{-/-}$retina, photoreceptor stress and degeneration is accompanied by a rapid infiltration of monocytes from the retinal vasculature. Recruitment occurs subsequent to increased CCL2 in the retina and several days before the resident microglial cells show any change in population size. Eliminating CCL2-CCR2 signaling blocked monocyte infiltration but did not alter the extent of degeneration. These results demonstrate that the immune response to neurodegeneration includes resident and infiltrated cells, even at very early times, and that monocyte involvement is not limited to disease states that overwhelm or deplete the resident microglial population and does not always hasten degeneration.

\section{Methods \\ Animals}

Mice were cared for and handled in accordance with the National Institutes of Health guidelines for the care and use of experimental animals and under approved protocols by the Institutional Animal Care and Use Committee of the University of California, Davis. All mice, including $\mathrm{Arr}^{-/-}$ [18] and wildtype C57BL/6J mice (Jackson Laboratories; Jax 000664), were born and raised in 24-h darkness prior to light exposure. Arr1 $1^{-/-}$mice were crossed with CCL2-RFP ${ }^{\text {lox/lox }}$ mice (Jax 016849) and PDGFRa-CRE mice (Jax 013148), creating $A r r 1^{-1-} C C L 2-R F P^{\text {lox } / l o x}$ PDGFRa$C R E^{-}$and $A r r 1^{-/-}$CCL2-RFP ${ }^{\text {lox/lox }}$ PDGFRa-CRE ${ }^{+}$mice that were sensitive to light, expressed a modified CCL2 gene tagged with a red fluorescent protein (mcherry), and, in $\mathrm{Cre}^{+}$mice, were deficient in Müller cell CCL2 expression. $A r r 1^{-/-}$mice were also crossed with $C C R 2^{r f p / r f p}$ mice (Jax 017586) to generate $A r r 1^{-/-} C C R 2^{+/ r f p}$ and $A r r 1^{-/-} C C R 2^{r f p / r f p}$ animals used for in vivo imaging and flow cytometry.

To initiate photoreceptor degeneration, adult mice between 2 and 5 months of age were exposed to homogeneous, continuous light of 75-200 lx for up to $240 \mathrm{~h}$. Both males and females were used; mice were screened for the rd8 mutation [26] and found to be lacking the mutation. Mice were euthanized by $\mathrm{CO}_{2}$ narcosis.

\section{Immunohistochemistry}

Following euthanasia, eyecups were dissected and fixed with $4 \%$ paraformaldehyde (PFA) in phosphate-buffered 
saline (PBS). Eyecups were stored in PBS at $4{ }^{\circ} \mathrm{C}$ at least overnight before connective tissue was trimmed off prior to sectioning. Eyecups were oriented to keep track of superior-inferior polarity while embedded in $4 \%$ low-melting agarose, then sectioned at $150 \mu \mathrm{m}$. Sections were blocked, incubated in primary antibodies overnight at $4{ }^{\circ} \mathrm{C}$, washed in PBS, then incubated in secondary antibodies with DAPI (R37606, Invitrogen) for 1.5-2 $h$ at room temperature. After an additional wash in PBS, sections were mounted onto slides in Prolong Diamond Antifade Mountant with DAPI (P36971, Invitrogen). Slides were visualized with a Nikon Ti-E A1 multiphoton imaging system using a $\times 40$-water immersion objective. Thirty-micrometer z-stacks and high-resolution images were sampled using NIS-Elements Microscope Imaging Software (Nikon). For IHC quantification, oblique sections were excluded from analysis. For each time point, between 2 and 9 sections from 2 to 3 mice per strain were quantified. Counts were standardized based on retinal area.

The following primary antibodies were used for IHC: rabbit anti-Iba1 (1:1000, 019-19741, Wako), rat anti-CD11b (1:300, ab24874, Abcam), mouse anti-Glutamine Synthetase (GS, 1:1000, MAB302, EMD Millipore), goat anti-CCL2/JE/ MCP-1 (1:300, AF-479-NA, R\&D Systems), and Alexa Fluor 647 anti-mouse/human CD11b (1:300, 101218, Biolegend). Secondary antibodies were diluted 1:300 and purchased from Invitrogen. Immunosera were diluted in a buffer of PBS with $0.5 \%$ bovine serum albumin and $0.5 \%$ Triton X-100.

\section{In vivo imaging and analysis}

For retinal imaging, the mice were initially anesthetized with $4 \%$ isoflurane, sustained at $2-2.5 \%$, and their body temperature maintained by heating pad $\left(37^{\circ} \mathrm{C}\right)$ attached to micropositioner (Phoenix Research Labs) that allowed rotational and translational adjustment for eye alignment. The pupils were dilated and cyclopleged with tropicamide and phenylephrine, and the corneal surface wetted with hypromellose gel (GenTeal Tears Severe, Alcon) and covered with a 0-Dpt. contact lens (Unicon Corporation).

A custom-built multimodal scanning laser ophthalmoscopy (SLO) and optical coherence tomography (OCT) system were used for all in vivo imaging [27]. Both SLO and OCT widefield images were collected over $51^{\circ}$ visual angle $(2.2 \mathrm{~mm})$. OCT imaging (100 B-scans and 2000 A-scans/B-scans) was used to monitor the retina during degeneration. OCT B-scan images were collected before light exposure (under dim red light used for alignment) and then after $24,48,72,96$, and $240 \mathrm{~h}$ of light exposure in the same animals. The OCT subsystem collects A-scans (single tomographic axial samples) at $100 \mathrm{kHz}$, with an axial resolution $\sim 2 \mu \mathrm{m}$, while the SLO and OCT subsystems have $x$-, $y$-analog resolutions of $\sim 3.5 \mu \mathrm{m}$, respectively. The OCT light source was centered at $860 \mathrm{~nm}$ with a 132-nm bandwidth (superluminescent diode, Broadlighter T-860HP; Superlum, Carrigtwohill, Cork, Ireland). To measure the thickness of retinal layers, all A-scan intensity profiles were averaged from the flattened OCT volume and evaluated using the choroid, INL, and RGC as landmarks.

For SLO images, multiple frames were averaged from wide-field images to increase visibility of retinal structures. To image $\mathrm{RFP}^{+}$cells in the CCR2-RFP ${ }^{+/ \mathrm{rfp}}$ mouse, SLO images were acquired using 560-nm excitation light (OBIS Laser, Coherent); back-reflected (retina morphology) and fluorescent light (RFP expressing cells) was collected using dichroic splitter (Semrock). To observe movement of $\mathrm{RFP}^{+}$cells in the vasculature and retina, we restricted the SLO acquisition field to $10-13^{\circ}$ visual angle $(457-556 \mu \mathrm{m})$ which resulted in increased pixel sampling density. The SLO frames were captured at 1.5 frames per second.

\section{EdU pulse}

Mice were given a single intraperitoneal (IP) injection of EdU (5-ethynyl-2'-deoxyuridine) at $100 \mathrm{mg} / \mathrm{kg}$ of $5 \mathrm{mg} / \mathrm{ml}$ concentration at light onset (time 0 ) and exposed to light for 0,24 , or $48 \mathrm{~h}$. After euthanasia, tissues were dissected and EdU was identified using the Click-iT EdU Alexa Fluor 647 Imaging Kit for IHC (C10640, Invitrogen) or the Click-iT EdU Pacific Blue Flow Cytometry Assay Kit for flow cytometry (C10418, Invitrogen) according to the manufacturer's instructions. For flow cytometry, each retina was considered a single sample, and up to 2.5 million events were collected; three blood samples, six retinas, and six choroids were used per time point, and collection was balanced such that at least one animal for each time point was quantified during each experimental run.

\section{Flow cytometry}

Flow cytometry was performed using a modified protocol based on O'Koren et al. [9]. Briefly, a tail-vein injection of either PE anti-mouse CD45 antibody (103106, BioLegend) or APC anti-mouse CD45 antibody (103112, BioLegend) was administered 5 min prior to euthanasia in order to label immune cells trapped in the circulating vasculature. Mice were euthanized by $\mathrm{CO}_{2}$ narcosis, and the retinas and RPE-choroid complex were digested in $1 \mathrm{~mL}$ of Hibernate medium (HBSS) (10-547F, Lonza) supplemented with 5\% fetal bovine serum (FBS), $10 \mathrm{mM}$ HEPES, $0.7 \mathrm{mg} / \mathrm{ml}$ calcium chloride, $1.5 \mathrm{mg} / \mathrm{ml}$ of Collagenase A (10103586001, Roche), and $0.1 \mathrm{mg} / \mathrm{ml}$ DNase I (10104159001, Roche). The tissue was digested at $37{ }^{\circ} \mathrm{C}$ for $15-20 \mathrm{~min}$, filtered through a $70-\mu \mathrm{m}$ cell strainer (25-276, Genesee Scientific), and resuspended in PBS. Cells were stained for viability (Zombie NIR Fixable Viability Kit, 423106, BioLegend) for 15-30 min; blocked with Fc block $1 \mathrm{ul} /$ sample (14-016186 , eBioscience), $5 \%$ normal rat serum, and 5\% normal mouse serum for $5 \mathrm{~min}$; then incubated with antibodies 
(1:100) at $37{ }^{\circ} \mathrm{C}$ for $60 \mathrm{~min}$. Antibody combinations varied depending on the experiment: APC anti-mouse CD45 (103112, BioLegend), Brilliant Violet (BV) 605 anti-mouse/ human CD11b (101257, BioLegend), BV 421 anti-mouse CX3CR1 (149023, BioLegend), BV 421 anti-mouse CD45 (103134, BioLegend), Alexa Fluor 488 anti-mouse Ly-6C (128022, BioLegend), PE/Cy7 anti-mouse CD192 (CCR2; 150612, BioLegend), BV 711 anti-mouse CX3CR1 (149031, BioLegend), and BV 711 anti-mouse I-A/I-E (107643, BioLegend). Antibody master mix was made in Brilliant Stain Buffer (563794, BD Biosciences). Cell suspensions were washed in $0.5 \%$ bovine serum albumin with 1:50 EDTA, and resuspended in Cell Staining Buffer (420201, BioLegend) with $0.5 \%$ PFA.

Bead controls were created using AbC Total Antibody Compensation Bead Kit (A10497, Invitrogen) and ArC Amine Reactive Compensation Bead Kit (A10628, Invitrogen). Data were acquired on a BD LSRII flow cytometer (BD Biosciences) and analyzed with FlowJo software (Tree Star). Each retina was considered a single sample, and all events, up to 2.5 million, were collected for each sample; a total of 3-5 blood samples, 6-9 retinas, and 6-9 choroids were collected per time point. Data collection was balanced such that at least one animal for each time point was quantified during each experimental run. The gating strategy was based on references [9, 28-32].

\section{Statistical analysis}

Statistical analyses were performed using R ( R core team, 2017, version 3.4.1). Results are presented as mean \pm SEM. A multiple-group comparison was performed using a one-way ANOVA followed by Tukey Honest Significant Differences post hoc test for all statistical analyses in the study. The significance level was set at $p<0.05$ (shown as $*$ in figures), $p<0.01{ }^{* * *}$ in figures) and $p<0.001$ (***; in figures).

\section{Multiple cytokine arrays}

The relative levels of 40 different cytokines were determined using mouse cytokine antibody array (Panel A, R\&D System), according to the manufacturer's protocol. Retinas were homogenized in PBS with protease inhibitors (cOmplete, mini, EDTA-free cocktail tablets, Roche). Samples were centrifuged at $\times 10,000 g$ for $5 \mathrm{~min}$ to remove cellular debris, and Triton X-100 was added to a final concentration of $1 \%$. Protein concentrations were quantified using total protein assay (Pierce $660 \mathrm{~nm}$ Protein Assay Kit, Thermo Fisher Scientific). Pre-mixed sample/antibody cocktails were incubated with blocked membranes overnight at $4{ }^{\circ} \mathrm{C}$ on a rocking platform shaker. After 3 washes, membranes were incubated with $800 \mathrm{CW}$ streptavidin (IRDye, LI-COR) for $30 \mathrm{~min}$ and washed 3 times before being scanned on the LI-COR odyssey imaging system. Data were analyzed with image studio lite 4.0 software
(LI-COR). The average fluorescent intensity of each cytokine was quantified for each retinal sample; the light-dependent changes in cytokine expression were determined by dividing the light-exposed values by those of the dark-reared samples processed in parallel from the same genotypes (WT and $A r r 1^{-/-}$) and performed in triplicate.

\section{ELISAs}

Retinas were homogenized in $100 \mu \mathrm{l}$ of PBS with protease inhibitors (cOmplete, mini, EDTA-free cocktail tablets, Roche) using sonication, then centrifuged at 14,000 rpm at $4{ }^{\circ} \mathrm{C}$ for $15 \mathrm{~min}$ to remove cellular debris. Protein concentrations were quantified using total protein assay (Pierce 660 nm Protein Assay Kit, Thermo Fisher Scientific). CCL2 levels were determined using the quantitative sandwich enzyme immunoassay technique (MJE00, R\&D Systems), according to the manufacturer's instructions. Both eyes from each animal were combined and tested as a single sample; $3-5$ mice were run for each time point.

\section{CCL2 neutralizing antibody injections}

After $12 \mathrm{~h}$ of light exposure, mice were anesthetized with $2-4 \%$ isoflurane mixed with oxygen. Pupils were dilated topically with $1 \%$ tropicamide and $2.5 \%$ phenylephrine ophthalmic solution. A small incision was made with the bevel of a 33-G needle, and a 2.5- $\mu$ l Hamilton syringe was used to inject $1.5-2 \mu \mathrm{l}$ of solution into the vitreous. Mice received either saline or $0.2 \mathrm{mg} / \mathrm{ml}$ goat anti-CCL2/JE/MCP-1 (1:300, AF-479-NA, R\&D Systems) in sterile saline.

\section{Results}

In vivo imaging reveals transient period of monocyte extravasation

In dark-reared mice lacking Arrestin-1, phototransduction signaling in retinal rods is greatly prolonged and results in light-induced photoreceptor degeneration from within an otherwise fully developed, normal retina ([18, 21]; Fig. 1a). The abrupt onset of widespread photoreceptor degeneration activates retinal microglia (Iba1, green; Fig. 1a), which migrate into the photoreceptor layers of the retina along a well-defined time course initiated by the onset of light (Fig. 1a, b) (see also [24]). By $36 \mathrm{~h}$, a significant fraction of $\mathrm{Iba}^{+}$cells had begun to engulf and presumably phagocytose photoreceptor cell bodies in the outer nuclear layer (ONL; Fig. 1c). After $96 \mathrm{~h}$ of light exposure, 40\% of the $\mathrm{Iba}^{+}$cells were located in the ONL and subretinal space (Fig. 1d, red and blue), in stark contrast to their normal position in the synaptic layers of dark-reared wildtype retinas, or $\mathrm{Arr}^{-/-}$retinas prior to light exposure (Fig. 1a, b). Wildtype mice processed in parallel did not show ONL thinning or changes in $\mathrm{Iba}^{+}$cells at any time point (Fig. 1b) (see also [24]). 

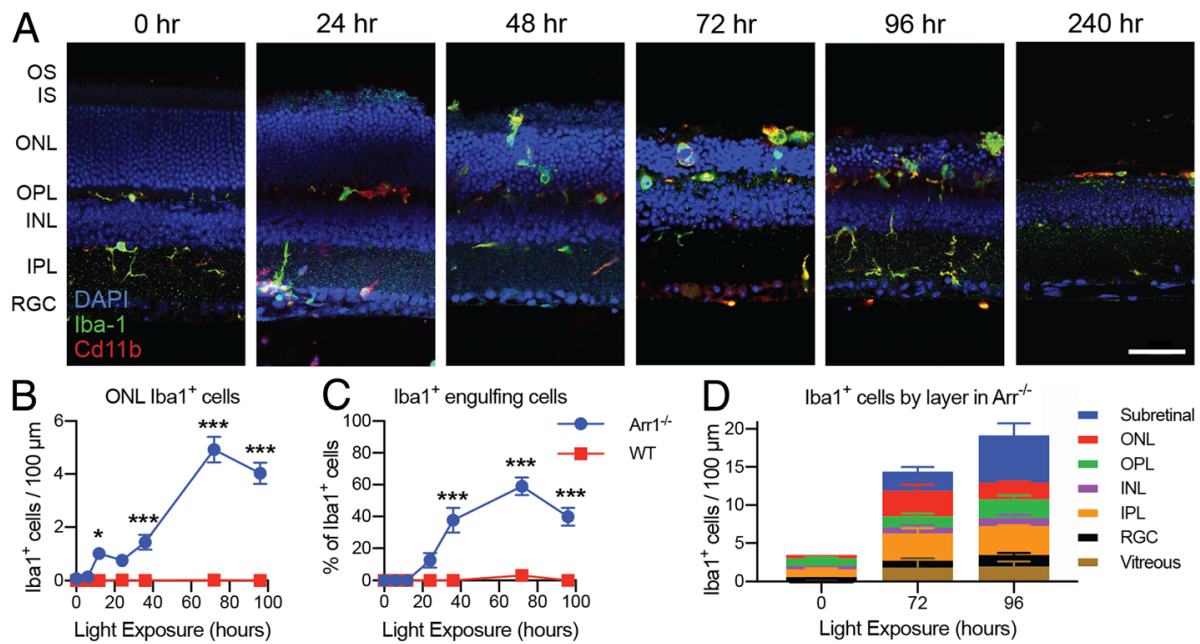

Fig. 1 Timecourse of microglia activation and photoreceptor clearance. a $I \mathrm{HC}$ of retinal sections of dark-reared $(0 \mathrm{~h})$ and light-exposed Arr ${ }^{-/-}$mice (24-240 h). Light induced widespread migration of Iba $1^{+}$cells (green) into the outer retina. By $72 \mathrm{~h}$, the outer retina (OS, IS, ONL) was markedly thinned and by $240 \mathrm{~h}$ had nearly vanished. $\mathbf{b}-\mathbf{d}$ Quantification of Iba $1^{+}$cells in $\mathrm{IHC}$ sections. $\mathbf{b}$ The number of Iba ${ }^{+}$cells in the ONL per $100 \mu \mathrm{m}$ increased significantly in two phases after light onset in $\mathrm{Arr}^{-1-}$ but did not change in dark-reared wild type (WT) controls. c The percent of Iba ${ }^{+}$ cells actively engulfing photoreceptors increased significantly at $36 \mathrm{~h}$ in Arr ${ }^{-/-}$and remained elevated through $96 \mathrm{~h}$; there was no change in WT. Data in B and C re-analyzed from Levine et al., 2014. $\mathbf{d}$ In Arr ${ }^{-1-}$ mice, the majority of Iba ${ }^{+}$cells in dark-reared animals ( $0 \mathrm{~h}$ ) were located in the plexiform layers, but after 72-96 h of light exposure, Iba $1^{+}$cells were also observed in the vitreous, RGC, ONL, and subretinal layers. Note that the discrepancy in quantification between 1B and 1D is due to the inclusion of subretinal and vitreal Iba $1^{+}$cells in 1D, which were not counted in the first study. Vitreal $\mathrm{Cd}_{1} 1 \mathrm{~b}^{+}$cells may include a population of hyalocytes. Scale bar is $50 \mu \mathrm{m}$ in A. OS photoreceptor outer segment layer, IS photoreceptor inner segment layer, ONL outer nuclear layer, OPL outer plexiform layer, INL inner nuclear layer, IPL inner plexiform layer, RGC retinal ganglion cell layer. ${ }^{*} p<0.05,{ }^{* *} p<0.01,{ }^{* * *} p<0.001$; error bars are SEM, $n=7-18$ locations per time point (locations selected from 3 to 9 sections across $2-3$ mice per strain per time)

The number of $\mathrm{Iba}^{+}$cells in the ONL appeared to increase in two distinct phases, an initial increase within $24 \mathrm{~h}$ and a slower rise that peaked at 72-96 $\mathrm{h}$, possibly reflecting both the migration of resident cells and the infiltration of monocytes, both of which can express Iba1. Indeed, close inspection of retinal sections co-stained for Cd11b revealed small round cells adhering along the vitreal surface of $\mathrm{ArrI}^{-/-}$retinas typical of monocyte morphology (Additional file 1: Figure S1A compare 0 to $24 \mathrm{~h}$ ). It is worth noting that $\mathrm{Cd}_{11} \mathrm{~b}^{+}$cells with a more pleiotropic morphology could be hyalocytes [33], the resident macrophage population of the vitreous, rather than monocytes. The infiltrates appeared most abundant at the optic nerve head and surrounding peripapillary region (Additional file 1: Figure S1B). The sudden appearance of infiltrating cells at the vitreoretinal surface was also readily observed in vivo using optical coherence tomography (OCT). Small, punctate light scattering signals appeared in the vitreous after $24 \mathrm{~h}$ of light exposure in $\mathrm{Arrl}^{-1-}$ mice, but not wildtype controls (Additional file 1: Figure S1C, arrows), consistent with an influx of immune cells from vessels at the retinal surface.

To further examine infiltration, mice expressing RFP behind the CCR2 promoter were bred into the $\mathrm{Arr}^{-1-}$ background $\left(\mathrm{Arr}^{-/-} \mathrm{CCR} 2^{+/ r f p}\right)$ and used to visualize monocytes within the retinal vessels in vivo with scanning laser ophthalmoscopy (SLO). Prior to the onset of degeneration $(0 \mathrm{~h}), \mathrm{RFP}^{+}$cells were only fleetingly visible in the retinal vasculature (Fig. 2a; Additional file 2: Video $0 \mathrm{~h}$ ). After $24 \mathrm{~h}$ of light exposure, $\mathrm{RFP}^{+}$cells were evident adhered to and rolling along the vessel walls (Fig. 2b, b'; Additional file 3: Video 24 h). Extended real-time in vivo imaging showed $\mathrm{RFP}^{+}$monocytes sometimes paused before detaching and re-entering the circulation, other times they rolled to a stop and extravasated through the vessel walls of the deep retinal capillaries (Fig. 2d; Additional file 4: Video ext 24 h). By 48 h, the retinal area outside the vessels was studded with round $\mathrm{RFP}^{+}$ cells that had extravasated and appeared to be mobile and migratory; many fewer cells were visible within the vessels than $24 \mathrm{~h}$ earlier (Fig. 2c, c'; Additional file 5: Video 48 h). Together, these data show that $\mathrm{CCR}^{+}$monocytes transiently adhere to the endothelial cells and extravasate from retinal vessels into the capillary plexus within the first $48 \mathrm{~h}$ of neurodegeneration.

\section{Infiltrating cells are recruited from retinal, not choroidal, vasculature}

Since photoreceptors are located closer to the choroidal vasculature than the vessels at the vitreoretinal surface, we examined the possibility that monocytes were also entering from the choroidal direction, across Bruch's 

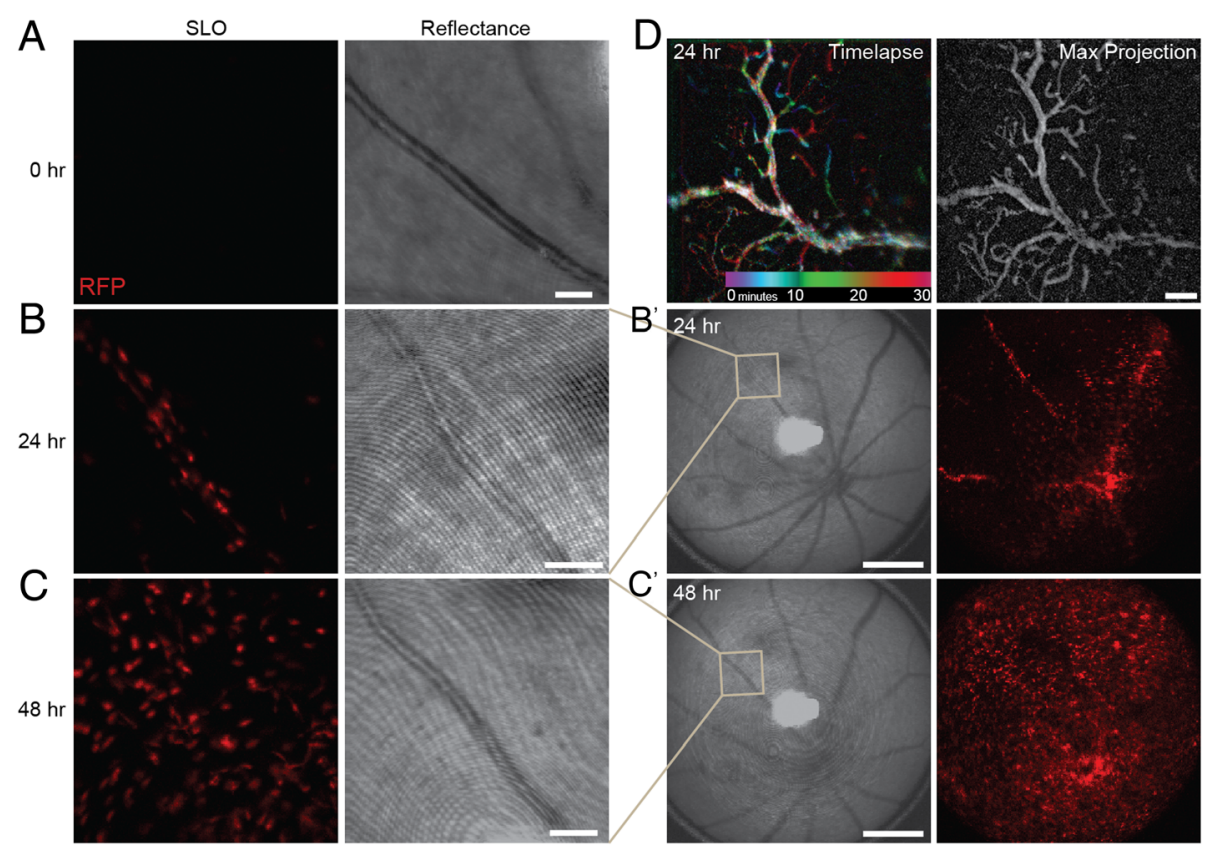

Fig. 2 In vivo imaging of monocyte infiltration through retinal vasculature during early neurodegeneration. In vivo retinal images of $\mathrm{Arr}^{-/-} \mathrm{CCR2^{+/rfp }}$ mice before and during photoreceptor degeneration. The fluorescence images (SLO) showed only fleeting RFP ${ }^{+}$signal prior to degeneration (a), but in the same vessel $24 \mathrm{~h}$ later, RFP ${ }^{+}$cells studded the interior (b) and could also be seen in other large caliber vessels and within the parenchyma of the central retinal ( $\mathbf{b}^{\prime}$ ). By $48 \mathrm{~h}, \mathrm{RFP}^{+}$cells had escaped the vasculature and appeared throughout the retina ( $\left.\mathbf{c}, \mathbf{c}^{\prime}\right)$. The bright field (reflectance) images taken concurrently with the fluorescence (SLO) show the position of the blood vessel in the same animal over time. SLO images are frames from Additional file 2: Video 0 h; Additional file 3: Video 24 h; Additional file 5: Video 48 h. (d) Color-coded representation of Additional file 4: Video ext $24 \mathrm{~h}$ (different Arr $7^{-/-}$ $C C R 2^{+/ \pi f p}$ animal, $24 \mathrm{~h}$ ), where each pixel was colorized based on the time epoch of the video in which RFP ${ }^{+}$cells appeared. The largest diameter vessel is largely white because the corresponding pixels were RFP ${ }^{+}$throughout the entire session due to persistent RFP ${ }^{+}$cell adherence to the vessel walls. Notice transient epochs of cell adherence to finer capillaries as revealed by streaks of blue, green, red, etc. The grayscale projection of maximal pixel intensities over time (right) outlines the vascular network in greater detail. Scale bars are $100 \mu \mathrm{m}$ in $\mathbf{a}, \mathbf{b}, \mathbf{c}, \mathbf{d}$, and $500 \mu \mathrm{m}$ in $\mathbf{b}^{\prime}, \mathbf{c}^{\prime}$

membrane, disrupting the retinal pigment epithelium (RPE). This would be difficult to detect by SLO and OCT because of the intrinsic light scattering by the melanin in the RPE and difficult to detect by standard immunohistochemistry (IHC). To determine where cells were infiltrating from, intraperitoneal injections of EdU were performed at light onset to label dividing cells, such as leuokocytes in the bloodstream. Retinal sections stained for EdU after $24 \mathrm{~h}$ of light exposure showed a high density of EdU ${ }^{+}$cells around the optic nerve head and within the adjacent vitreous but not in the outer retinal layers or choroid of $\mathrm{Arrl}^{-/-}$mice (Fig. 3a). No EdU ${ }^{+}$cells were evident in dark-reared wildtype (WT) mice treated in parallel, consistent with no cell division or infiltration in healthy retina. EdU pulses initiated at later time points (e.g., 24 or $48 \mathrm{~h}$ ) incorporated into circulating leukocytes but did not appear in the retina (data not shown), supporting the existence of a short, transient period of extravasation evident by $\mathrm{IHC}$ and in vivo imaging (Figs. 1, 2, and 3).

To quantify EdU ${ }^{+}$cells in $\mathrm{Arr}^{-/-}$mice, we used flow cytometry on dissociated retina, choroid, and blood samples at light onset $(0 \mathrm{~h})$ and afterwards (24, 48 h) (Fig. 3b, c).
Negligible numbers of EdU ${ }^{+}$cells were detected initially $(0 \mathrm{~h})$ since EdU would not have had time to incorporate into newly synthesized DNA. By $24 \mathrm{~h}$, there were abundant EdU $^{+}$cells in the blood, consistent with normal leukocyte proliferation. Notably, $\mathrm{EdU}^{+}$cells were also abundant in the retina at $24 \mathrm{~h}$, but not in the choroid, indicating that $\mathrm{EdU}^{+}$ cells from the bloodstream were not entering the retina through the choroidal compartment. In both blood and retinal samples, fewer EdU ${ }^{+}$cells were measured at $48 \mathrm{~h}$, presumably because the population of labeled cells was turning over (Fig. 3c). These data demonstrate that infiltrating cells rapidly enter through the retinal vasculature as opposed to the choroidal vasculature within $24 \mathrm{~h}$ of neurodegeneration onset (Fig. 1b) (see also [24]).

\section{CD $45^{\text {high }}$ cells rapidly increase in the retina during early neurodegeneration}

To identify the specific classes of cells infiltrating the retina, we used a flow cytometry gating strategy similar to those described in O'Koren et al. [9] on samples of retina, choroid, and blood from $A r r 1^{-/-}$mice exposed to $0,24,48,72$, or $96 \mathrm{~h}$ of light. Cells trapped within the vasculature at the time of dissection were labeled with a 

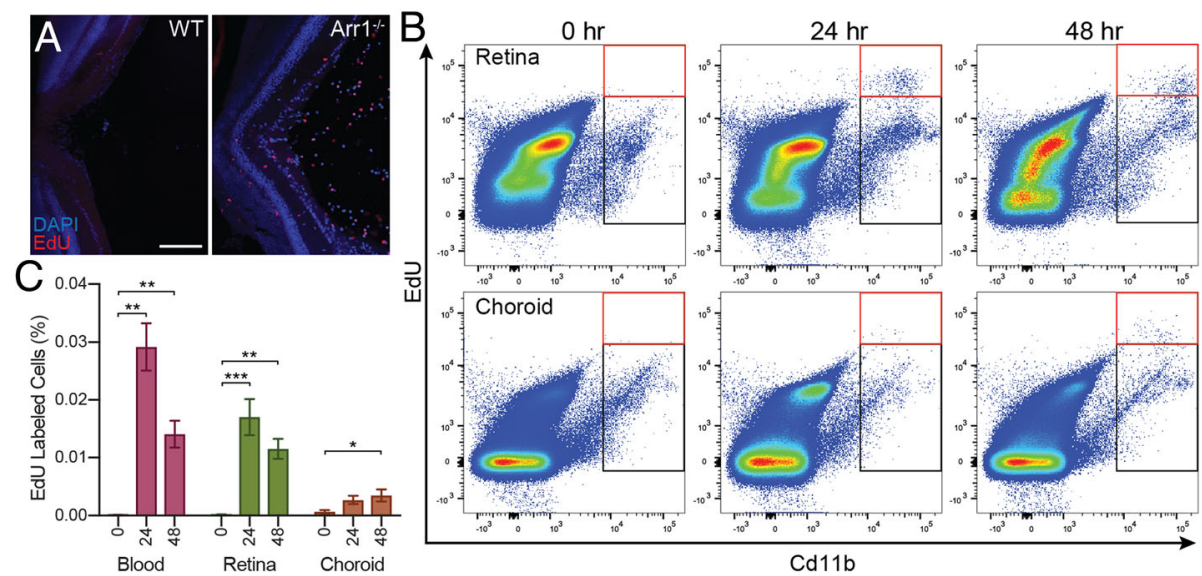

Fig. 3 Infiltrating cells are recruited from the retinal vasculature. To determine whether leukocytes were primarily infiltrating through the retinal vasculature or the choroidal vasculature, IP injections of EdU were performed at light onset to label dividing cells. a IHC of a section through the optic nerve head of WT and Arr ${ }^{-1-}$ retinas at $24 \mathrm{~h}$ showed EdU staining (red) predominantly of infiltrating cells at the vitreoretinal surface of Arr ${ }^{-1-}$ mice. Scale bar $100 \mu \mathrm{m}$. Similar results were observed in 2-3 sections from 2 to 4 mice of both genotypes. b Flow cytometry was used to quantify CD1 $1 \mathrm{~b}^{+}$EdU ${ }^{+}$cells (red box) from retina, choroid, and blood of Arr $1^{-1-}$ mice. Black box indicates the number of CD1 $1 \mathrm{~b}^{+}$not labeled with EdU. c CD11 b EdU labeled cells were abundant in the retina at 24 and $48 \mathrm{~h}$. In contrast, $C D 11 \mathrm{~b}^{+}$EdU $\mathrm{U}^{+}$cells in the choroid did not significantly increase until $48 \mathrm{~h}$ and even then were far more rare than in blood and retina. Blood samples were used to verify EdU incorporation and, as expected, showed a significant increase at 24 and 48 h. ${ }^{*} p<0.05,{ }^{* *} p<0.01,{ }^{* * *} p<0.001$; error bars are SEM from 3 mice (blood) or 6 retina/choroid per time point

fluorescently tagged antibody to CD45 (leukocyte common antigen) injected intravenously just before euthanasia. We will refer to the "In Vasculature" population stained by the intravenously delivered CD45 antibody as "CD45-IV" to distinguish it from $\mathrm{CD} 45^{+}$cells outside of the vasculature, which were labeled subsequently with a separate fluorescently tagged antibody after dissociation.

Samples were gated by SSC, FSC, and Live/Dead fluorescence to identify alive, single cells (Fig. 4a, scatter plots). There was a progressive decrease in the number of alive, single cells in the retinal samples after light onset, reflecting the on-going photoreceptor degeneration (Fig. 4a, light gray), and consistent with the retinal thinning seen by IHC and OCT in vivo imaging. In contrast, there were no significant changes in the number of alive, single cells harvested from choroid or blood over time (Fig. 4a, medium/dark gray).

To isolate and quantify immune cell subtypes, samples were gated by $\mathrm{Cd} 11 \mathrm{~b}$ and $\mathrm{CD} 45$ expression, which included CD45-IV ${ }^{+}$cells (Fig. 4b). Prior to the onset of degeneration $(t=0)$, there were very few $\mathrm{Cd} 11 \mathrm{~b}^{+} \mathrm{CD} 45^{\text {high }}$ cells in the retina, but by $24 \mathrm{~h}$, the number had increased dramatically and remained well above baseline even after $96 \mathrm{~h}$ (Fig. 4b, c, light orange). In contrast, there was a large population of $\mathrm{Cd} 11 \mathrm{~b}^{+} \mathrm{CD} 45^{\text {high }}$ cells in both the choroid and blood samples prior to the onset of degeneration (Fig. 4b, medium/dark orange) and no significant change in either group at later times, indicating that the pools of immune cells within these compartments were unperturbed by the rapid degeneration occurring on the other side of the blood-retinal barrier. The number of cells in the retinal sample that were $\mathrm{Cd} 11 \mathrm{~b}^{+} \mathrm{CD} 45^{\text {low }}$, which includes resident retinal immune cells like microglia, remained remarkably constant through the first $72 \mathrm{~h}$, then showed a significant population increase at $96 \mathrm{~h}$ (Fig. 4c, green).

\section{Resident immune cell populations are stable during early retinal degeneration}

The constancy of $\mathrm{Cd} 11 \mathrm{~b}^{+} \mathrm{CD} 45^{\text {low }}$ retinal cell numbers during the early stages of degeneration (Fig. 4c) led us to examine this population further for discernible subpopulations that might be changing concurrently. First, CD $45^{\text {low }}$ cells were gated on $\mathrm{Ly}_{6} \mathrm{C}^{-}$and $\mathrm{Cx} 3 \mathrm{CR} 1^{+}$expression (Fig. 5a, b). Next, cells were gated on Major Histocompatibility Complex class II (MHC-II), which is normally found on antigen-presenting cells such as macrophages, and CD45-IV, which only labeled cells within or associated with the vasculature at the time of tissue harvest. As expected, very few Ly6C $^{-}$cells were stained by the CD45-IV antibody injection (Fig. 5b, right), consistent with the $\mathrm{CD} 45^{\text {low }} \mathrm{Ly} 6 \mathrm{C}^{-}$cells being a resident population. Cells that were $\mathrm{Cd}_{11} \mathrm{~b}^{+} \mathrm{CD} 45^{\text {low }} \mathrm{Ly} \mathrm{C}^{-} \mathrm{Cx} 3 \mathrm{CR} 1^{+}$ $\mathrm{CD} 45-\mathrm{IV}^{-}$and $\mathrm{MHC}-\mathrm{II}^{\text {low }}$, which included the vast majority of microglial cells, remained at a constant level for the first $72 \mathrm{~h}$ of degeneration, increasing above baseline only at $96 \mathrm{~h}$ (Fig. 5c). These data indicate that microglial proliferation did not occur within the first $72 \mathrm{~h}$, despite widespread microglial activation and photoreceptor phagocytosis (Fig. 1). Likewise, the number of cells that 

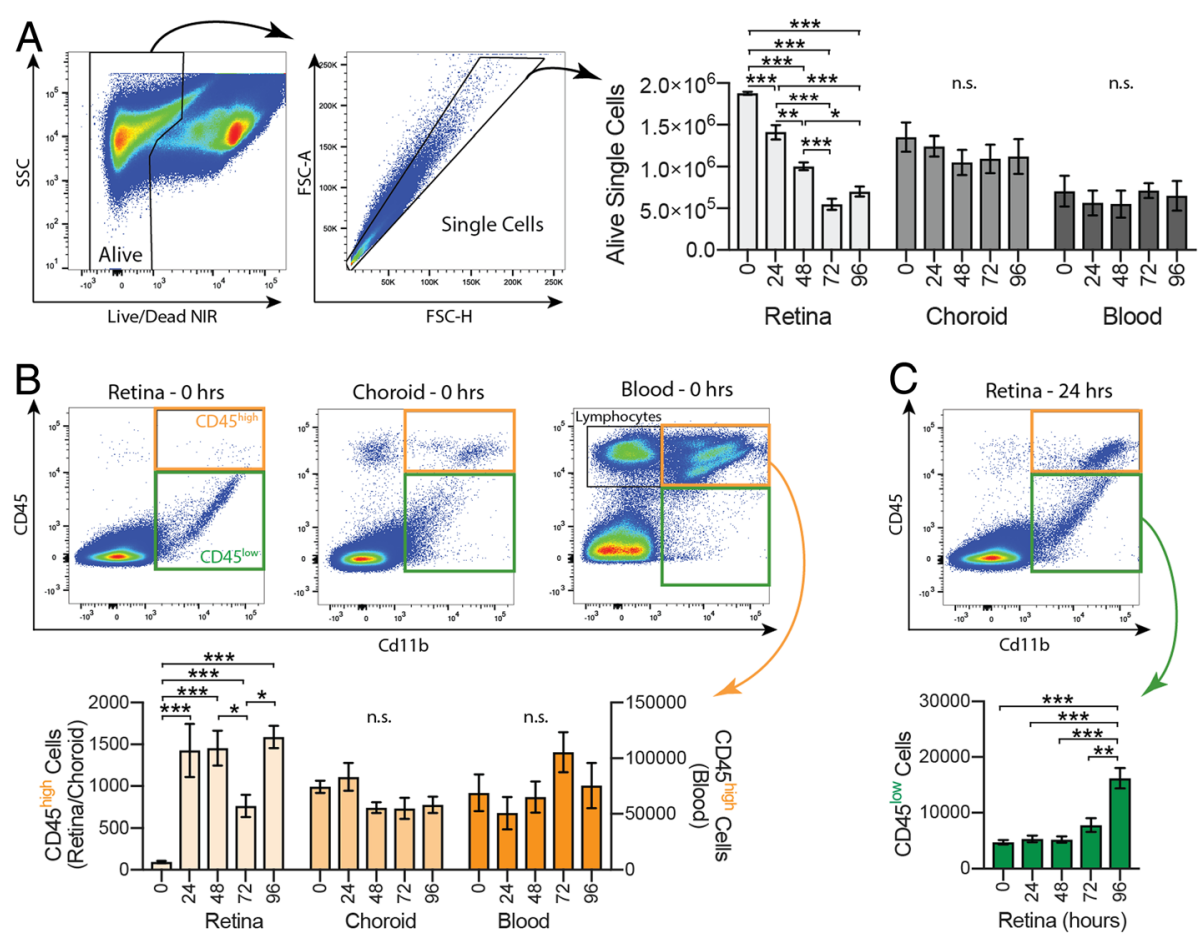

Fig. 4 Increased Cd11 $b^{+} \mathrm{CD} 45^{\text {high }}$ cells during early neurodegeneration. Flow cytometry was used to identify cell types recruited during retinal degeneration. a Dissociated cell suspensions were gated to select alive, single cells. There was a significant decrease in the number of alive, single cells in the retinal samples at all time points except between 72 and $96 \mathrm{~h}$ (light gray), but no significant difference in the choroid (medium gray) or blood (dark gray) samples. b Cd1 $1 b^{+}$cells were gated into CD $45^{\text {high }}$ (orange) and CD $45^{\text {low }}$ (green) populations. There were very few $\mathrm{Cd} 11 \mathrm{~b}^{+} \mathrm{CD} 45^{\text {high }}$ cells in the retina at $0 \mathrm{~h}$ (light orange); however, by $24 \mathrm{~h}$ the number increased dramatically and remained well above baseline at $96 \mathrm{~h}$. There were no significant changes in the choroid (medium orange) or blood (dark orange). $\mathbf{c}$ The number of retinal $\mathrm{Cd} 11 \mathrm{~b}^{+} \mathrm{CD} 45^{\text {low }}$ cells (green) remained constant through the first $72 \mathrm{~h}$, then showed a significant population increase at $96 \mathrm{~h} .{ }^{*} p<0.05,{ }^{*} p<0.01,{ }^{* * *} p<0.001$; n.s. $=$ not significant; error bars are SEM from 3 to 5 mice (blood) or 6-9 retinas/choroids per time point

were MHC-II ${ }^{\text {high }}$, which include macrophages [9] and putative resident dendritic cells [34], was unchanged during early degeneration, increasing only at $96 \mathrm{~h}$ (Fig. 5d). Together, these results demonstrate that the number of resident immune cells in the retina is stable throughout early neurodegeneration, even during a dramatic period of neuronal cell death.

\section{Infiltrating cells are primarily CD45 ${ }^{\text {high }}$ Ly6C ${ }^{\text {high }}$ monocytes}

To define the molecular phenotypes of infiltrating cells, retinal $\mathrm{Cd} 11 \mathrm{~b}^{+} \mathrm{CD} 45^{\text {high }}$ cells (Fig. 4b, light orange) were gated on Ly6C, Cx3CR1, CCR2, and CD45-IV expression (Fig. 6a, b). The number of $\mathrm{Cd}_{11} \mathrm{~b}^{+} \mathrm{CD} 45^{\text {high }}$ CD45-IV $\mathrm{IV}^{-} \mathrm{C}^{\text {high }}$ cells, which include classical monocytes, increased dramatically by $24 \mathrm{~h}$ and remained high before falling at $72 \mathrm{~h}$ (Fig. $6 \mathrm{c}$, red). In contrast $\mathrm{Cd} 11 \mathrm{~b}^{+}$ CD45 high $\mathrm{CD}^{4} 5-\mathrm{IV}^{-}$Ly6C ${ }^{\text {low }}$ cells were far less abundant at early times, slowly increasing over the first $48 \mathrm{~h}$ before abruptly doubling between 72 and 96 h (Fig. 6d blue). Because there was not a corresponding, preceding abrupt increase in Ly6C ${ }^{\text {high }}$ cells at $72 \mathrm{~h}$ (Fig. 6c), the doubling of Ly6C ${ }^{\text {low }}$ cells likely reflects proliferation of infiltrated cells between 72 and $96 \mathrm{~h}$, coincident with the $\sim 2$-fold increase of CD $45^{\text {low }}$ resident cells observed at this time (Fig. 5c, d).

Notably, the population of Ly6C $\mathrm{C}^{\text {high }}$ cells in the retina declined as the population of $\mathrm{Ly} 6 \mathrm{C}^{\text {low }}$ cells increased (compare Fig. 6c, d), suggesting that Ly6C $C^{\text {high }}$ cells downregulated Ly6C as they transformed upon entering the retina. To see whether Ly6C $\mathrm{C}^{\text {low }}$ cells were arising from in-residence transformation rather than recruitment, we examined the Ly6C status of monocytes trapped within the retinal vessels at the time of tissue harvest. Because cells adherent to the vessels were stained by CD45-IV, we quantified the number of $\mathrm{CD} 45-\mathrm{IV}^{+}$cells within the Ly6 $\mathrm{C}^{\text {high }}$ and Ly6C $\mathrm{C}^{\text {low }}$ subpopulations (Fig. 6a, b, yellow boxes). After $24 \mathrm{~h}$, there was a sharp increase in the number of $\mathrm{CD} 45-\mathrm{IV}^{+}$Ly6 $\mathrm{C}^{\text {high }}$ cells in the retinal samples (Fig. 6e). The number of CD45-IV ${ }^{+}$Ly6C $\mathrm{C}^{\text {high }}$ cells decreased dramatically between 24 and $48 \mathrm{~h}$, but had not returned to baseline by $96 \mathrm{~h}$; in contrast, the number of CD45-IV Ly6 $\mathrm{C}^{\text {low }}$ cells increased only slightly at $24 \mathrm{~h}$ then dropped back to baseline. The total number of Ly6 $\mathrm{C}^{\text {high }}$ and Ly6 $\mathrm{C}^{\text {low }}$ cells in the blood did not change over time $(p=0.5572$, $p=0.3381$, respectively). These results demonstrate that Ly6C $C^{\text {high }}$ circulating immune cells were preferentially 

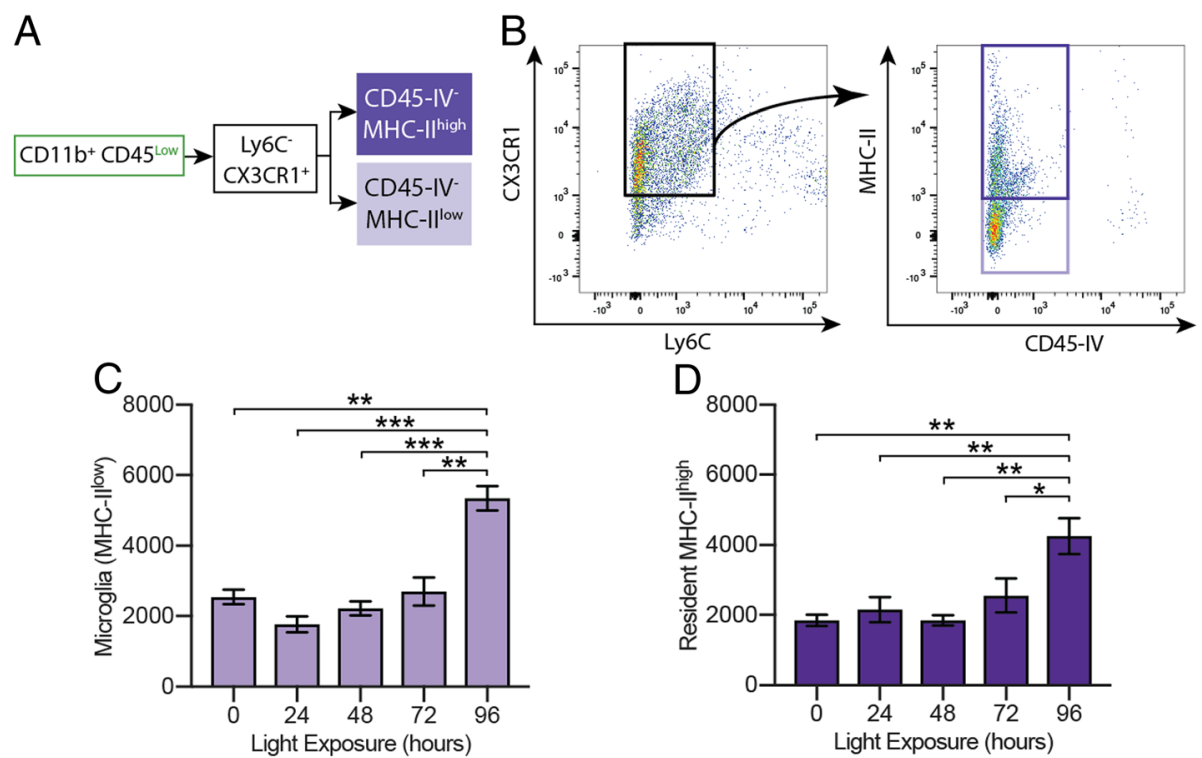

Fig. 5 Microglia numbers are stable during a dramatic period of cell clearance. $\mathbf{a}, \mathbf{b}$ CD $45^{\text {low }}$ populations were gated on Ly6C and Cx3CR1 expression; MHC-II was used to distinguish microglia from resident macrophages, and CD45-IV was used to remove cells within or associated with the vasculature. c Microglia, the resident MHC-Ilow cells, remained at constant for the first $72 \mathrm{~h}$, then increased at $96 \mathrm{~h}$ (lavender). $\mathbf{d}$ The number of resident MHC-II ${ }^{\text {high }}$ cells was also stable until $96 \mathrm{~h}$ (dark purple). Together, these data show that the number of resident immune cells is stable during early retinal degeneration. ${ }^{*} p<0.05,{ }^{* *} p<0.01,{ }^{* * *} p<0.001$; error bars are SEM, $n=6-9$ retinas per time point
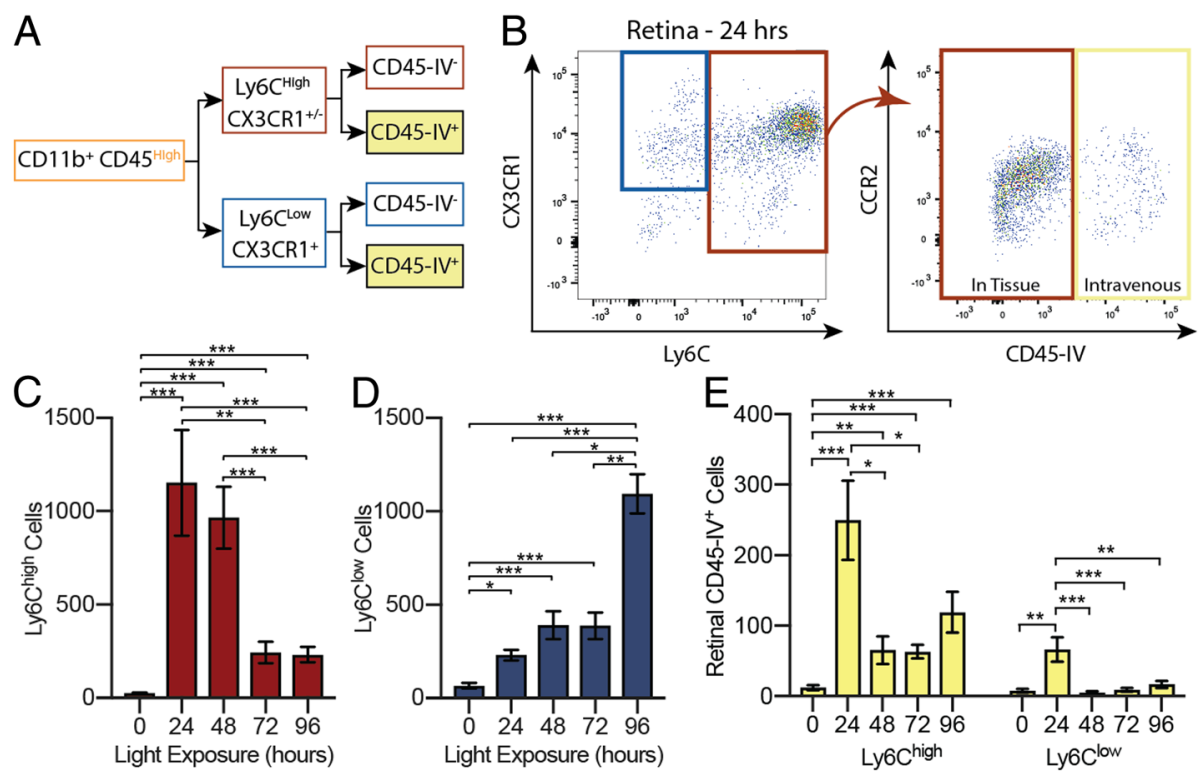

Fig. 6 Infiltrating cells are primarily CCR2 $2^{+}$Ly6C Chigh . a, b CD45 high populations were gated on Ly6C, CX3CR1, CCR2, and CD45-IV expression. c The number of Ly6C high cells increased dramatically at $24 \mathrm{~h}$ and remained high before falling at 72 and $96 \mathrm{~h}$ (red). $\mathbf{d}$ Ly6Clow cells were less abundant at early times, slowly increasing over the first $48 \mathrm{~h}$ before abruptly doubling between 72 and $96 \mathrm{~h}$ (blue). e CD45-IV ${ }^{+}$populations from retinal samples were examined to determine the Ly6C status of cells trapped within the retinal vasculature (yellow). The number of Ly6C ${ }^{\text {high }}$ cells increased sharply by $24 \mathrm{~h}$ and did not return to baseline by $96 \mathrm{~h}$; the number of Ly6Clow cells increased briefly at $24 \mathrm{~h}$ before returning to baseline. ${ }^{*} p<0.05,{ }^{* *} p<0.01,{ }^{* * *} p<0.001$; error bars are SEM, $n=6-9$ retinas per time point 
adhering to the retinal vasculature throughout degeneration, but particularly at $24 \mathrm{~h}$, while few Ly $6 \mathrm{C}^{\text {low }}$ cells adhered only briefly at $24 \mathrm{~h}$. This further supports the idea that the late-appearing Ly6 ${ }^{\text {low }}$ population (Fig. $6 \mathrm{~d}$ ) arose from transformation of the Ly6 $\mathrm{C}^{\text {high }}$ population within the retina.

\section{Circulating immune cells are recruited via CCL2-CCR2-mediated signaling}

To begin to identify the signaling mechanism(s) that attract microglia and monocytes to the ONL, we used a 40-chemokine array to screen changes in retinal cytokine expression. After $12 \mathrm{~h}$ of light exposure, only four cytokines showed any appreciable change in $\mathrm{Arrl}^{-/-}$mice. CCL2, previously Monocyte Chemoattractant Protein (MCP-1), changed the most dramatically, increasing approximately 4-fold (Fig. 7a, b; Additional file 6: Table S1). Two other cytokines involved in polymorphonuclear leukocyte recruitment, namely CCL3 and CXCL2, also showed a slight increase in expression. CCL3, previously Macrophage Inflammatory Protein 1-alpha (MIP-1 $\alpha)$, is involved in inflammatory recruitment and activation of granulocytes, and CXCL2, previously Macrophage Inflammatory Protein 2-alpha (MIP-2), is a chemoattractant secreted by monocytes and macrophages. The only cytokine that decreased at $12 \mathrm{~h}$ in $\mathrm{Arrl}^{-/-}$mice was CD54, previously Intercellular Adhesion Molecule-1 (ICAM-1), which is a cell adhesion molecule present on the surface of endothelial cells and leukocytes involved in transendothelial migration.

Since CCL2 showed the most substantial change, we used ELISAs to validate the chemokine array and to quantify CCL2 levels in the retina over the course of degeneration. CCL2 expression peaked $18 \mathrm{~h}$ after light onset and slowly returned to baseline by $72 \mathrm{~h}$ (Fig. 7c), despite continued light exposure and on-going retinal thinning. In contrast, dark-reared WT mice exposed to light in parallel showed no change in cytokine expression in either the cytokine array or ELISAs (Fig. 7a-c; Additional file 6: Table S1).

To determine the source CCL2, we performed IHC on $A r r 1^{-1-}$ retinas. Staining for CCL2 was undetectable in dark-reared $\mathrm{Arrl}^{-/-}$retinas, but diffuse staining appeared after $18 \mathrm{~h}$ of light exposure, particularly in the inner nuclear and retinal ganglion cell layers (Fig. 7d, green). Particularly strong CCL2 staining was evident in individual cells that resembled Müller glia cells (Fig. 7d, red), consistent with other models of retinal degeneration [35].

Next, we used a conditional ablation strategy to completely eliminate Müller glia-derived CCL2 [36]. Arr1 ${ }^{-/-}$ $C C L 2-R F P^{l o x / l o x}$ mice expressing a fluorescently tagged CCL2 and flanked by loxP sites were crossed with a mouse containing Cre recombinase targeted to Müller glia cells $\left(\mathrm{Arrl}^{-/}{ }^{-}\right.$CCL2-RFP ${ }^{\text {lox/lox }}$ PDGFRa-Cre ${ }^{+}$mice). After $24 \mathrm{~h}$ of light exposure, $\mathrm{Arr1}^{-/-}$CCL2-RFP ${ }^{\text {lox/lox }}$ PDGFRa-Cre mice showed widespread CCL2 staining throughout the retina
(Fig. 7e, green), whereas $A r r 1^{-/-}$CCL2-RFP ${ }^{\text {lox/lox }}$ PDGFRa$\mathrm{Cre}^{+}$mice showed almost no detectable CCL2 within the retinal layers; only a small amount of punctate CCL2 staining remained. This punctate staining was also $\mathrm{Cd}_{11} \mathrm{~b}^{+}$, consistent with these cells being a small number of remaining infiltrating cells (Fig. 7f, green). Further, the absence of detectable CCL2 staining in Müller cell-specific CCL2 knockout retinas indicates that RPE-derived CCL2 did not measurably contribute to retinal CCL2 levels. By $48 \mathrm{~h}$, retinal CCL2 expression had dramatically decreased in Cre-negative mice (Fig. 7e, f, bottom panels), consistent with the transient CCL2 expression quantified by ELISA (Fig. 7c). Together, these data show that Müller glia transiently express CCL2 during the initial phase of the retinal degeneration and further reveal them to be the predominant source of retinal CCL2.

To test whether circulating immune cells were being recruited through CCL2-CCR2 mediated signaling, we used $A r r 1^{-/-} C C R 2^{r f p / r f p}$ knock out mice that expressed RFP in lieu of functional CCR2 receptors. Infiltrating cells were quantified using a modified flow cytometry panel that accounted for the RFP fluorescence and gated as previously described. Removing CCR2-mediated signaling caused an almost complete loss of $\mathrm{CD} 11 \mathrm{~b}^{+} \mathrm{CD} 45^{\text {high }}$ cells recruited to the retina in $A r r 1^{-/-} C C R 2^{r f p / r f p}$ mice at 24 and $48 \mathrm{~h}$ (Fig. $7 \mathrm{~g}$ ). This was true of both Ly6Chigh and Ly6 $\mathrm{C}^{\text {low }}$ subpopulations (Fig. 7h). In addition, using immunohistochemistry, we quantified the density of $\mathrm{CD}_{11 b^{+}}$cells within the retina of the Müller cell-specific CCL2 knockout $\left(\mathrm{Arr1}^{-/-}\right.$CCL2-RFP ${ }^{\text {lox } / l o x}$ PDGFRa-Cre ${ }^{+}$vs $\mathrm{Arr}^{-/-}$CCL2-RFP ${ }^{\text {lox/lox }}$ PDGFRa-Cre ; Fig. 7e, f). At $48 \mathrm{~h}$ after the onset of degeneration, the density of Cd11b + cells was significantly reduced $\left(\mathrm{Cre}^{-} 1.20 \times 10^{-4} \mathrm{cells} / \mu \mathrm{m}^{2}+/-\right.$ $1.8 \times 10^{-6}$ vs. $\mathrm{Cre}^{+} 9.03 \times 10^{-5}$ cells $/ \mu \mathrm{m}^{2}+/-4.8 \times 10^{-6}$; $p=0.0097 ; n=4$ sections from 2 eyes per strain), indicating that blocking Müller cell CCL2 expression also reduced monocyte infiltration. Together, these data show that monocytes are recruited during neurodegeneration through a CCR2-mediated signaling pathway, likely in direct response to the release of CCL2 by Müller glia cells.

\section{Eliminating CCL2-CCR2 signaling did not alter the rate of retinal thinning}

To determine the effect of eliminating CCL2-CCR2 mediated recruitment, we measured the rate of retinal thinning in $\mathrm{Arr}^{-/-} \mathrm{CCR} 2^{r f p / r f p}$ mice using in vivo OCT imaging. Surprisingly, the rate of thinning did not significantly change in mice lacking functional CCR2 receptors. Instead the photoreceptor layer degenerated at the same rate in $A r r 1^{-/-}$mice (Fig. 7i, dark blue), Arr1 $1^{-/-} C C R 2^{+/ r f p}$ heterozygotes (black), and $A r r 1^{-/-} C C R 2^{r f p / r f p}$ homozygous knockouts (brown). These data indicate that blocking the infiltration of monocytes had no effect on the rate of neurodegeneration. 


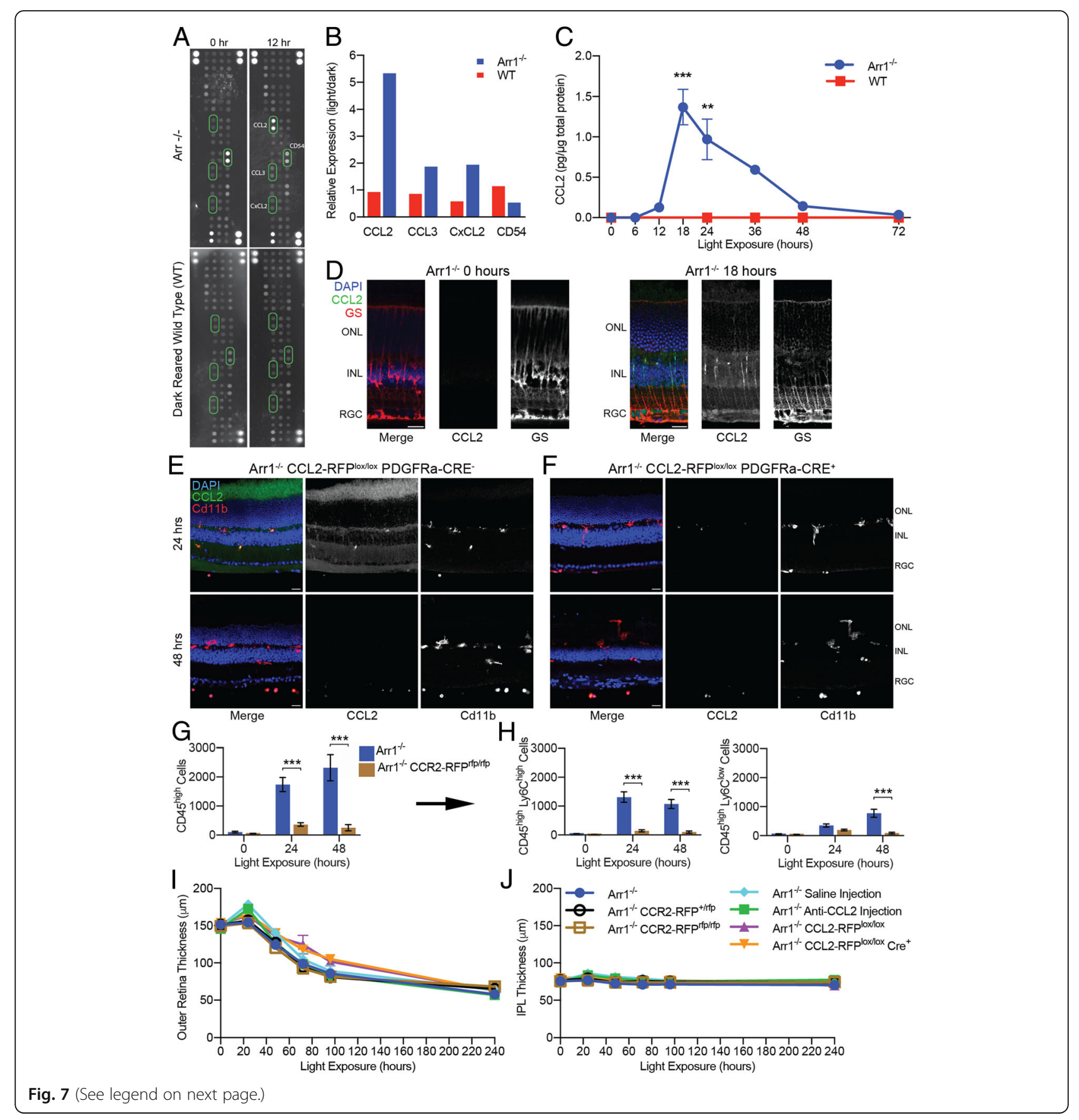


(See figure on previous page.)

Fig. 7 CCL2-CCR2 mediated signaling recruits monocytes but does not limit the rate of retinal thinning. $\mathbf{a}$, $\mathbf{b}$ Cytokine array screening of retinal homogenates of dark-reared Arr $1^{-/-}$and WT mice before $(0 \mathrm{~h})$ and after $12 \mathrm{~h}$ of light exposure. There were few light-dependent changes overall, other than a striking increase in CCL2 expression in $\mathrm{Arr}^{-1-}$ retinas. Representative results from 8 blots, 4 from each genotype. c ELISA analysis of dark-reared $\mathrm{Arr}^{-1-}$ and WT mice revealed that CCL2 levels rose rapidly after $12 \mathrm{~h}$ of light exposure, peaking at $18 \mathrm{~h}(n=3-5 \mathrm{mice}$ per time point). d $\mathrm{IHC}$ of retinal sections of dark-reared $\left(\mathrm{O} \mathrm{h}\right.$ ) and light-exposed (18 h) $\mathrm{Arr}^{-1-}$ mice showed early CCL2 expression (green) in Müller glial cells (red). e Expression of fluorescently tagged CCL2 (green) was observed abundantly throughout the retina at $24 \mathrm{~h}$ but not at $48 \mathrm{~h}$, consistent with the previous IHC and ELISA data. $\mathbf{f}$ In PDGFRa-Cre ${ }^{+}$mice, the LoxP sites flanking CCL2 were excised only in Müller glia cells, preventing these cells from producing CCL2, and resulting in an almost complete absence of CCL2 in the retina of Cre ${ }^{+}$mice at $24 \mathrm{~h}$. Only punctate staining was observed in circulating and infiltrating monocytes, which did not lose their ability to produce CCL2. Representative images from 2 to 3 sections from 2 mice per strain per time point. These data demonstrate that Müller glia cells are the primary producers of CCL2 in the retina. $\mathbf{g}$ Knocking out CCR2, the primary receptor for CCL2, resulted in an almost complete loss of recruited CD45 high cells. $\mathbf{h}$ There was a significant loss of both CD45 high Ly6C $C^{\text {high }}$ and CD45 high Ly6Clow subpopulations ( $n=4-6$ retinas per strain per time point). $\mathbf{i}, \mathbf{j}$ In vivo OCT B-scans were used to measure the thickness of the outer and inner retinal layers during degeneration. i Blocking CCL2-CCR2 signaling did not affect the extent of outer retinal

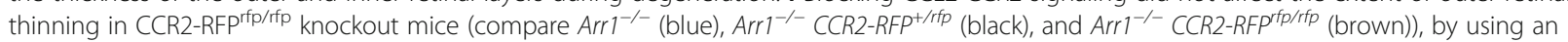
intravitreal injection of CCL2 neutralizing antibody (compare saline (light blue) to anti-CCL2 (green)), or with a conditional CCL2 knockout in Müller glia (compare Arr1 ${ }^{-1}$ CCL2-RFPlox/lox PDGFRa-Cre (purple) to Arr1 ${ }^{-/-}$CCL2-RFPlox/lox PDGFRa-Cre $^{+}$(orange)). $\mathbf{j}$ No appreciable change was detected in the thickness of the inner plexiform layer (IPL) in any of the mice, confirming that retinal degeneration was limited to the photoreceptor layer ( $n=3-4$ retinas from 2 mice per strain per time point). Error bars represent SEM; ${ }^{* *} p<0.01,{ }^{* * *} p<0.001$; ONL outer nuclear layer, INL inner nuclear layer, RGC retinal ganglion cell layer. Scale bar is $20 \mu \mathrm{m}$ in $\mathbf{d}-\mathbf{f}$

Next, we examined the consequence of blocking CCL2 directly using two different strategies. First, we injected a neutralizing antibody intravitreally during the rising phase of CCL2 expression to block CCL2 function. IHC confirmed that a single injection of CCL2-neutralizing antibody remained in the eye for at least $12 \mathrm{~h}$ (Additional file 7 : Figure S2). Despite the blockade, in vivo OCT imaging found no significant effect on the overall rate of retinal thinning (Fig. 7i, j; compare saline injected (light blue) vs anti-CCL2 injected (green).

Finally, we used conditional CCL2 ablation mice $\left(\mathrm{Arrl}^{-/}\right.$CCL2-RFP ${ }^{\text {lox } / \text { lox }}$ PDGFRa-Cre ${ }^{+}$) to completely eliminate Müller glia-derived CCL2 (Fig. 7e, f). In vivo OCT imaging detected no change in the rate of retinal thinning between $\mathrm{Arr}^{-/-}$CCL2-RFP $\mathrm{P}^{\mathrm{lox} / \text { lox }}$ PDGFRa-Cre and $\mathrm{Arrl}^{-1-}$ CCL2-RFP ${ }^{\text {lox } / l o x}$ PDGFRa-Cre ${ }^{+}$mice (Fig. 7i; compare lox/lox $\mathrm{Cre}^{-}$(purple) to lox/lox $\mathrm{Cre}^{+}$(orange)); the photoreceptor layer degenerated at the same rate in CCL2-deficient mice as in experimentally matched controls, while the inner plexiform layer thickness did not change (Fig. 7i, j).

Thus, despite the large, transient increase in CCL2 expression by Müller cells and evidence that blocking the CCL2-CCR2 signaling reduced the influx of CD45 $5^{\text {high }}$ cells, neurodegeneration proceeded unabated. Unlike other retinal damage studies in which monocytes exacerbate degeneration [14, 37, 38], our results demonstrate that monocyte infiltration does not necessarily further harm or control the rate of neurodegeneration.

\section{Discussion}

We have shown that during the onset of retinal degeneration, there are two distinct and simultaneous immune responses: (1) the en mass activation and migration of microglial cells to the degenerating neurons (Fig. 1) (see also [24]) and (2) a transient period of peripheral cell infiltration through the retinal vasculature, primarily of classical CD45 ${ }^{\text {high }}$ Ly6 $\mathrm{C}^{+}$monocytes (Figs. 2, 3, 4, and 6). Blocking CCL2-CCR2 signaling disrupts the recruitment of monocytes, but does not rescue the phenotype or change the rate of neurodegeneration (Fig. 7). Thus, the emergent picture of neuroinflammation during acute degeneration is one of marked heterogeneity, involving the interplay of microglia, glia, and infiltrating monocytes throughout the course of disease progression. Here, we discuss our findings in the context of CCL2-CCR2-mediated recruitment by Müller glia, the extravasation of monocytes through the retinal vasculature, and the role of recruited immune cells during neuronal death, with an emphasis on the implications of our results for other forms of neurodegenerative disease.

\section{CCL2 as a glial-mediated signaling molecule for neuroinflammation}

Arrestin-1 is a photoreceptor-specific protein responsible for deactivating light-driven rhodopsin activity [18]. The deletion of Arrestin-1 causes widespread photoreceptor degeneration [21] and synchronized, rapid morphological transformation of retinal microglia [24]. The signal(s) inducing microglial migration to the photoreceptors are not yet known. Here, cytokine arrays, ELISAs, IHC, and conditional knockout of retinal CCL2 show that CCL2 is rapidly expressed by Müller cells, the radial glia of the retina. Although CCL2 staining was observed in the photoreceptor layer in $\mathrm{Arr1}^{-/} C \mathrm{CL} 2-\mathrm{RFP} \mathrm{P}^{\text {lox/lox }}$ PDGFRa-Cre mice (Fig. 7e), consistent with previous studies [39], when Müller glia cells lost their ability to produce CCL2 (in PDGFRa-Cre ${ }^{+}$mice), this staining disappeared (Fig. 7f). This indicates that Müller cell-derived CCL2 diffuses throughout the neural retina and that photoreceptors, retinal pigment 
epithelium (RPE), and microglia are not the predominant sources of CCL2 in the retina at the onset of degeneration.

Although neuroinflammation is typically thought to result from the interaction of microglia and monocytes with dying neurons, our work shows that radial glial cells can act as conduits for relaying stress and death signals beyond the site of degeneration. Müller radial glia are perfectly poised to detect physiological changes accompanying photoreceptor stress through their intimate and numerous contacts with the photoreceptor inner segments and extensive contacts with retinal vessels, which help create the vitreoretinal barrier known as the inner limiting membrane (reviewed in [40]). Therefore, Müller cells, like microglia, can be considered "first responders" to neuronal injury and degeneration.

Concurrent with the peak expression of CCL2 in Müller cells, our in vivo SLO imaging of $\mathrm{Arr}^{-/-} \mathrm{CCR} 2^{+/ r f p}$ mice show that $\mathrm{CCR}^{+}$monocytes adhere to the endothelial cells of retinal vessels within $24 \mathrm{~h}$ of light onset (Fig. 2, Additional file 2: Video 0 h; Additional file 3: Video $24 \mathrm{~h}$; Additional file 4: Video ext $24 \mathrm{~h}$; Additional file 5: Video $48 \mathrm{~h}$ ). As the rate of degeneration slowed over $48-72 \mathrm{~h}$ (Fig. 4a, light gray bars; Fig. 7i), the level of CCL2 returned to baseline and the number of infiltrating $\mathrm{CD} 45^{\text {high }}$ Ly6C ${ }^{\text {high }}$ cells decreased (Fig. 6). Eliminating CCL2-CCR2 signaling using $A r r 1^{-/-} C C R 2^{r f p / r f p}$ mice resulted in a significant drop in the recruitment of $\mathrm{CD} 45^{\text {high }}$ monocytes from the blood stream (Fig. 7g), confirming that signaling through the CCL2-CCR2 pathway was responsible for recruitment, consistent with other models [37]. Together these data demonstrate that Müller glia cells respond to retinal neurodegeneration by releasing CCL2, which recruits circulating immune cells to the site of degeneration through the CCL2-CCR2 signaling pathway and that disrupting this pathway prevents the recruitment of monocytes.

\section{Early response to neurodegeneration dominated by CD45 ${ }^{\text {high }}$ Ly6C ${ }^{\text {high }}$ monocytes}

Contrary to expectations, the CD $45^{\text {high }}$ Ly6 $\mathrm{C}^{\text {high }}$ infiltrating cells did not enter through the choroid, but rather through the retinal vasculature and optic nerve head (Figs. 2 and 3, Additional file 1: Figure S1), despite the fact that the degeneration was happening in the deeper photoreceptor layers of the retina. This is similar to the way that monocytes enter the eye through the optic nerve head during retinal ganglion cell degeneration in a slower model of neurodegeneration of early glaucoma [41].

Interestingly, the number of resident immune cells in the retina $\left(\mathrm{Cd} 11 \mathrm{~b}^{+} \mathrm{CD} 45^{\text {low }} \mathrm{Ly}_{6 \mathrm{C}^{-}} \mathrm{Cx} 3 \mathrm{CR} 1^{+}\right)$was remarkably constant for the first 3 days of degeneration, a time during which approximately $40 \%$ of the outer retina thickness disappeared (Figs. 1a and 7i) and monocytes invaded the retina. The resident immune cell population consisted of two subpopulations: $\mathrm{MHC}-\mathrm{II}^{\text {low }}$, composed primarily of microglia, and MHC-II ${ }^{\text {high }}$, which includes perivascular macrophages and a small, robust population of dendritic cells $[34,42]$ or a long-lived population of putative macrophages that express high levels of MHC-II [9]. Thus, if the monocytes that infiltrated at $24 \mathrm{~h}$ rapidly transformed into macrophages (MHC-II ${ }^{\text {high }}$ cells) or microglia-like cells $\left(\mathrm{MHC}-\mathrm{II}^{\mathrm{low}}\right)$, they either must have replaced cells that were dying or kept high levels of CD45 expression. Further, it was not until between 72 and $96 \mathrm{~h}$ after degeneration onset that the total number of $\mathrm{CD} 45^{\text {low }}$ cells substantially increased (and roughly doubled), suggesting a distinct, late phase of cell proliferation in both MHC-II ${ }^{\text {low }}$ and MHC-II ${ }^{\text {high }}$ subclasses (Fig. 5c, d). Thus, although microglia were the first to migrate to the site of retinal injury, their population did not increase in size until neurodegeneration had proceeded for $96 \mathrm{~h}$. Instead, the dominant responders were the peripheral monocytes, which began infiltrating within $24 \mathrm{~h}$.

Monocytes were abundant in the retina at 24 and $48 \mathrm{~h}$ (Fig. 6c). Many of the newly extravasated cells expressed CCR2, but the population was heterogeneous (Fig. 6b). By $72 \mathrm{~h}$, there were roughly twice as many $\mathrm{Ly}^{-} \mathrm{C}^{-}$cells than $\mathrm{Ly}_{6 \mathrm{C}} \mathrm{C}^{+}$, and by $96 \mathrm{~h}$, the discrepancy was more than 4-fold (Fig. 6d). This is consistent with other models of neurodegeneration that have shown $\mathrm{Ly}_{6} \mathrm{C}^{+}$classical monocytes, and inflammatory monocytes can infiltrate tissue and differentiate into pro-inflammatory macrophages and dendritic cells $([43,44]$ for review). The disproportioned jump in the $\mathrm{Ly} 6 \mathrm{C}^{\mathrm{low}}$ population at $96 \mathrm{~h}$ is similar to the increase observed in the resident population, suggesting that the infiltrating and resident populations proliferated in synchrony. Together, these data demonstrate that the identities of immune cells in the degenerating retina become highly intertwined and heterogeneous once degeneration is initiated, both in terms of lineage (yolk sac-derived microglia vs bone marrow-derived monocytes) and tissue-specific transcriptional regulation [45].

\section{Neurodegeneration proceeds independent of monocyte recruitment}

Despite acting as the dominant responder, the elimination of monocytes did not affect the duration of neurodegeneration. We employed three different experimental techniques to eliminate CCL2-CCR2 signaling, yet despite evidence that infiltration was blocked (Fig. $7 \mathrm{~g}$ ), the photoreceptor layer degenerated at the same rate in CCL2-deficient mice and CCR2-deficient mice as in experimentally matched controls (Fig. 7i), indicating that the influx of monocytes had no effect on the outcome of neurodegeneration.

One possible reason that blocking CCL2-CCR2 signaling in $\mathrm{Arrl}^{-/-}$did not alter neurodegeneration may be because the rate of degeneration is intrinsic to the mechanism of cell death within the photoreceptors rather than driven by the immune response. The loss of Arrestin-1 only affects 
photoreceptors, rendering them more than 200-fold more sensitive to light than normal [18] and causing them to die even in dim light (25 lx, without dilated pupils) [24]. The degeneration is a cell-autonomous process, initiated all at once by light onset. This differs from diseases that are slowly progressive, like retinitis pigmentosa or age-related macular degeneration, in which photoreceptor stress is cumulative and may be more sensitive to immune system modulation.

Another fundamental difference between the $\mathrm{Arrl}^{-/-}$ model and studies that have implicated CCL2-CCR2 as an important mediator of retinal health is the degree to which the damage is limited to a single cell type. The loss of photoreceptors in $A r r 1^{-/-}$mice occurs at light levels that do not cause photolytic damage (75-200 lx, undilated pupils of pigmented mice) or stress the regenerative capacity of the RPE, at least at the early times being considered in this study. This is in contrast to studies that inflicted broader damage, such as Rutar and colleagues [37], who suppressed retinal CCL2 levels with small interfering RNA (siRNA) and found a reduced the number of apoptotic photoreceptors induced by bright light (1000 lx, dilated pupils); Sennlaub and colleagues [14] who knocked out CCL2 and rescued photoreceptor degeneration caused by light stress (4500 lx, dilated pupils); or $\mathrm{Hu}$ and colleagues [38] who knocked out CCR2 and found significant structural and functional preservation of the retina after exposure to blue light-induced damage (500 lx, daily for 3 days). The exclusive damage to photoreceptors is presumably why CCL2 is one of only a handful of cytokines that change in the $\mathrm{ArrI}^{-/-}$at early times (Fig. 7a-c; Additional file 6: Table S1), rather than the noted upregulation of a broad spectrum of chemokines in other studies (e.g., CCL3, CCL4, CCL7, CXCL1, and CXCL10) [46, 47].

Given the interest in developing therapies that target cytokine cascades during retinal disease, the specificity of the $\mathrm{Arr}^{-/-}$model provides a notable opportunity to examine the consequences of immune system intervention in a targeted, cell-autonomous model of neurodegeneration. This is critical for determining the effects of cytokine interventions on cell type-specific genetic disorders, for understanding the mechanism(s) by which peripheral cells invade the CNS during disease progression, and for interpreting the consequences of these cells on disease progression during neurodegeneration, particularly if modulation of the innate immune system is to be a viable therapeutic target for neurodegenerative disease (e.g., $[48,49])$.

\section{Conclusions}

Here, we show that in the $A r r 1^{-/-}$retina, the induction of photoreceptor degeneration causes a transient infiltration of monocytes from the retinal vasculature within $24 \mathrm{~h}$. Recruitment occurs after the increase in retinal CCL2 and several days before the resident microglial cells show any change in population size. Microglia and monocyte proliferation occur concurrently, but not until several days after the onset of neurodegeneration, when the rate of cell death has slowed. Eliminating CCL2-CCR2 signaling blocked monocyte infiltration but did not alter the extent of degeneration. These results demonstrate that the immune response to neurodegeneration includes both resident and infiltrated cells, even at very early times and that monocyte involvement is not limited to disease states that overwhelm or deplete the resident microglial population and does not always hasten degeneration.

\section{Additional files}

\begin{abstract}
Additional file 1: Figure S1. Monocyte infiltration occurs through retinal vasculature and the optic nerve head. (A) Low and high magnification views of retinal $I \mathrm{HC}$ sections from $\mathrm{Arr}^{-/-}$mice before $(0 \mathrm{~h})$ and after $24 \mathrm{~h}$ of light exposure. Note the appearance of small round cells along the vitreal surface after $24 \mathrm{~h}$. Scale bar $200 \mu \mathrm{m}$. (B) $\mathrm{IHC}$ from sections through the optic nerve head $(\mathrm{ONH})$ of $\mathrm{Arr}^{-1-}$ retina. Infiltrating cells, many of which were $\mathrm{Cd}_{11} \mathrm{~b}^{+}$(red), clustered around the $\mathrm{ONH}$ and optic stalk. Vitreal $\mathrm{Cd}_{11} \mathrm{~b}^{+}$cells may include a population of hyalocytes. Scale bar $50 \mu \mathrm{m}$. (C) In vivo OCT imaging detected infiltrating cells in the vitreous (arrows), near the optic stalk and peripapillary region, in $\mathrm{Arr}^{-/}$ but not wildtype mice. Similar results were seen in more than 6 other mice at this time point. (PNG $3160 \mathrm{~kb}$ )

Additional file 2: Video $0 \mathrm{~h}$. In vivo imaging of monocyte infiltration at $0 \mathrm{~h}$. The fluorescence image (SLO) showed only fleeting $\mathrm{RFP}^{+}$signal prior to degeneration $(0 \mathrm{~h})$, indicating that under normal conditions, $\mathrm{RFP}^{+}$cells course through the vasculature at a rapid rate. Cells were pseudocolored red; scale bar given in Fig. 2a. (AVI 4330 kb)
\end{abstract}

Additional file 3: Video $24 \mathrm{~h}$. In vivo imaging of monocyte infiltration at $24 \mathrm{~h}$. By $24 \mathrm{~h}, \mathrm{RFP}^{+}$cells studded the interior of the retinal vessel, adhering to the retinal walls and slowly rolling along the interior surface. Recorded from the same vessel shown at $0 \mathrm{~h}$, which had previously shown only fleeting $\mathrm{RFP}^{+}$cells. Cells were pseudocolored red; scale bar given in Fig. 2b. (AVI 5926 kb)

Additional file 4: Video extended $24 \mathrm{~h}$. In vivo imaging of monocyte infiltration at $24 \mathrm{~h}$. Extended, wide-field video at $24 \mathrm{~h}$ taken in a different mouse than the previous videos. RFP ${ }^{+}$cells can be seen coursing through large caliber vessels, periodically pausing and adhering to the vessel walls. $\mathrm{RFP}^{+}$cells are also evident in the parenchyma of the central retina. A color-coded time-lapse, where each pixel is colorized based on the time epoch of the video, and a max projection image are given in Fig. $2 \mathrm{~d}$. Scale bar is $100 \mu \mathrm{m}$. (AVl $36713 \mathrm{~kb}$ )

Additional file 5: Video $48 \mathrm{~h}$. In vivo imaging of monocyte infiltration at 48 h. By 48 h, RFP ${ }^{+}$cells had escaped the vasculature and appeared slowly moving throughout the retina. In addition, rapidly moving RFP ${ }^{+}$ cells are evident coursing through the vasculature more quickly than previously observed at $24 \mathrm{~h}$. Recorded from the same vessels shown at $0 \mathrm{~h}$ and $24 \mathrm{~h}$. Cells were pseudocolored red; scale bar given in Fig. 2c. (AVI $7900 \mathrm{~kb}$ )

Additional file 6: Table S1. Changes in chemokine expression after $12 \mathrm{~h}$ of light exposure. A 40-chemokine array was used to screen for cytokine expression in degenerating $\mathrm{Arr}^{-1-}$ retinas after $12 \mathrm{~h}$ of light exposure. Very few cytokines showed any appreciable change compared to dark-reared WT controls. The most dramatic was CCL2, which showed a 5.3-fold increase. Relative expression levels were calculated as light-exposure divided by dark reared for each group, then averaged across runs. A value of 1 indicates no change; shades of red are greater than 1.5, and shades of blue are less than 0.6. (DOCX $15 \mathrm{~kb}$ )

Additional file 7: Figure S2. CCL2-neutralizing antibody remains in the eye for at least $12 \mathrm{~h}$. A single injection of CCL2-neutralizing antibody $12 \mathrm{~h}$ after light onset was used to block CCL2 signaling intravitreally. 
Flat-mounted retinae were stained with a fluorescently tagged secondary antibody (green) capable of binding to intravitreally injected CCL2 antibody after 1 (B) or 12 (C) hours from the time of injection, demonstrating that the injected antibody remained in the eye. No staining was seen in the saline-injected control (A), verifying that the secondary did not bind indiscriminately. Scale bar is $500 \mu \mathrm{m}$. (PNG $755 \mathrm{~kb}$ )

\section{Abbreviations}

IHC: Immunohistochemistry; INL: Inner nuclear layer; IPL: Inner plexiform layer; IS: Photoreceptor inner segment layer; OCT: Optical coherence tomography; ONL: Outer nuclear layer; OPL: Outer plexiform layer; OS: Photoreceptor outer segment layer; PBS: Phosphate-buffered saline; PFA: Paraformaldehyde; RFP: Red fluorescent protein; RGC: Retinal ganglion cell layer; RPE: Retinal pigment epithelium; SEM: Standard error of the mean; SLO: Scanning laser ophthalmoscopy; WT: Dark-reared wildtype

\section{Acknowledgements}

We thank Pengfei Zhang and Mayank Goswami for their early help with in vivo imaging, Kaitryn E. Ronning and Karli Ching for their help with the dissociations of retina and choroid, Bridget McLaughlin for their assistance with flow cytometry, and Profs. Edward Pugh and Daniel Saban for their helpful discussions and comments on an earlier version of the manuscript.

\section{Funding}

This work was supported by the National Eye Institute (R01-EY24320), the NEl UC Davis Core grant (P30-EY012576), National Institutes of Health Training Grants (T32-GM007377; T32-EY105387), and the UC Davis Flow Cytometry Core (NIH S100D018223).

\section{Availability of data and materials}

The datasets used and/or analyzed during the current study are available from the corresponding author on reasonable request.

\section{Authors' contributions}

SJK designed and executed all of the experiments, analysis, and figure preparation, unless otherwise indicated here, and wrote and edited the paper. EBM performed cytokine screening and analysis, in vivo imaging and analysis, retinal thickness measurements, drafted the in vivo imaging methods, and participated in intellectual discussions. XW assisted in designing, conducting, and analyzing the flowcytometry experiments. ESL performed immunohistochemistry quantification and wrote an early first draft of the paper. RJZ provided in vivo instrumentation, training, and expertise. MEB guided experimental design, oversaw data interpretation, and wrote and edited the manuscript. All authors read and approved the final manuscript.

\section{Ethics approval}

Mice were cared for and handled in accordance with the National Institutes of Health guidelines for the care and use of experimental animals and under approved protocols by the Institutional Animal Care and Use Committee of the University of California, Davis.

\section{Consent for publication}

Not applicable

\section{Competing interests}

The authors declare that they have no competing interests.

\section{Publisher's Note}

Springer Nature remains neutral with regard to jurisdictional claims in published maps and institutional affiliations.

\section{Author details}

'Department of Cell Biology and Human Anatomy, University of California, Davis, 1 Shields Avenue, Davis, CA 95616, USA. ${ }^{2}$ Center for Neuroscience, University of California, Davis, 1544 Newton Court, Davis, CA 95618, USA. ${ }^{3}$ Department of Ophthalmology \& Vision Science, University of California, Davis, 1 Shields Avenue, Davis, CA 95616, USA.
Received: 9 August 2018 Accepted: 11 November 2018 Published online: 15 December 2018

\section{References}

1. Schafer DP, Stevens B. Microglia function in central nervous system development and plasticity. Cold Spring Harb Perspect Biol. 2015;7:a020545.

2. Prinz M, Priller J. Microglia and brain macrophages in the molecular age: from origin to neuropsychiatric disease. Nat Rev Neurosci. 2014;15:300-12.

3. Karlstetter M, Scholz R, Rutar M, Wong WT, Provis JM, Langmann T. Retinal microglia: just bystander or target for therapy? Prog Retin Eye Res. 2015;45: 30-57.

4. Michell-Robinson MA, Touil H, Healy LM, Owen DR, Durafourt BA, Bar-Or A, Antel JP, Moore CS. Roles of microglia in brain development, tissue maintenance and repair. Brain. 2015;138:1138-59.

5. Wolf SA, Boddeke HW, Kettenmann H. Microglia in physiology and disease. Annu Rev Physiol. 2017;79:619-43.

6. Wang X, Zhao L, Zhang J, Fariss RN, Ma W, Kretschmer F, Wang M, Qian HH, Badea TC, Diamond JS, et al. Requirement for microglia for the maintenance of synaptic function and integrity in the mature retina. J Neurosci. 2016;36: 2827-42.

7. Hanisch UK, Kettenmann H. Microglia: active sensor and versatile effector cells in the normal and pathologic brain. Nat Neurosci. 2007:10:1387-94.

8. Jin N, Gao L, Fan X, Xu H. Friend or foe? Resident microglia vs bone marrow-derived microglia and their roles in the retinal degeneration. Mol Neurobiol. 2017;54:4094-112.

9. O'Koren EG, Mathew R, Saban DR. Fate mapping reveals that microglia and recruited monocyte-derived macrophages are definitively distinguishable by phenotype in the retina. Sci Rep. 2016;6:20636.

10. Chen M, Zhao J, Luo C, Pandi SP, Penalva RG, Fitzgerald DC, Xu H. Para-inflammation-mediated retinal recruitment of bone marrow-derived myeloid cells following whole-body irradiation is CCL2 dependent. Glia. 2012;60:833-42.

11. Ajami B, Bennett JL, Krieger C, Tetzlaff W, Rossi FM. Local self-renewal can sustain CNS microglia maintenance and function throughout adult life. Nat Neurosci. 2007:10:1538-43.

12. Mildner A, Schmidt H, Nitsche M, Merkler D, Hanisch UK, Mack M, Heikenwalder M, Bruck W, Priller J, Prinz M. Microglia in the adult brain arise from Ly-6ChiCCR2+ monocytes only under defined host conditions. Nat Neurosci. 2007:10:1544-53.

13. Moreno MA, Burns T, Yao P, Miers L, Pleasure D, Soulika AM. Therapeutic depletion of monocyte-derived cells protects from long-term axonal loss in experimental autoimmune encephalomyelitis. J Neuroimmunol. 2016;290:36-46.

14. Sennlaub F, Auvynet C, Calippe B, Lavalette S, Poupel L, Hu SJ, Dominguez E, Camelo S, Levy O, Guyon E, et al. CCR2(+) monocytes infiltrate atrophic lesions in age-related macular disease and mediate photoreceptor degeneration in experimental subretinal inflammation in $\mathrm{Cx} 3 \mathrm{cr} 1$ deficient mice. EMBO Mol Med. 2013;5:1775-93.

15. Gordon S, Taylor PR. Monocyte and macrophage heterogeneity. Nat Rev Immunol. 2005;5:953-64.

16. Herz J, Filiano AJ, Smith A, Yogev N, Kipnis J. Myeloid cells in the central nervous system. Immunity. 2017;46:943-56.

17. Baufeld C, O'Loughlin E, Calcagno N, Madore C, Butovsky O. Differential contribution of microglia and monocytes in neurodegenerative diseases. J Neural Transm (Vienna). 2018;125(5):809-26.

18. Xu J, Dodd RL, Makino CL, Simon Ml, Baylor DA, Chen J. Prolonged photoresponses in transgenic mouse rods lacking arrestin. Nature. 1997;389:505-9.

19. Wilden U, Kuhn H. Light-dependent phosphorylation of rhodopsin: number of phosphorylation sites. Biochemistry. 1982;21:3014-22.

20. Chen J, Simon MI, Matthes MT, Yasumura D, LaVail MM. Increased susceptibility to light damage in an arrestin knockout mouse model of Oguchi disease (stationary night blindness). Invest Ophthalmol Vis Sci. 1999; 40:2978-82.

21. Hao W, Wenzel A, Obin MS, Chen CK, Brill E, Krasnoperova NV, Eversole-Cire P, Kleyner $Y$, Taylor A, Simon MI, et al. Evidence for two apoptotic pathways in light-induced retinal degeneration. Nat Genet. 2002;32:254-60.

22. Burns ME, Mendez A, Chen CK, Almuete A, Quillinan N, Simon Ml, Baylor DA, Chen J. Deactivation of phosphorylated and nonphosphorylated rhodopsin by arrestin splice variants. J Neurosci. 2006:26:1036-44.

23. Wang T, Chen J. Induction of the unfolded protein response by constitutive G-protein signaling in rod photoreceptor cells. J Biol Chem. 2014:289: 29310-21. 
24. Levine ES, Zam A, Zhang P, Pechko A, Wang X, FitzGerald P, Pugh EN Jr, Zawadzki RJ, Burns ME. Rapid light-induced activation of retinal microglia in mice lacking Arrestin-1. Vis Res. 2014;102:71-9.

25. Dias MF, Joo K, Kemp JA, Fialho SL, da Silva Cunha A Jr, Woo SJ, Kwon YJ. Molecular genetics and emerging therapies for retinitis pigmentosa: basic research and clinical perspectives. Prog Retin Eye Res. 2018;63:107-31.

26. Mattapallil MJ, Wawrousek EF, Chan CC, Zhao H, Roychoudhury J, Ferguson TA, Caspi RR. The Rd8 mutation of the Crb1 gene is present in vendor lines of C57BL/6N mice and embryonic stem cells, and confounds ocular induced mutant phenotypes. Invest Ophthalmol Vis Sci. 2012;53:2921-7.

27. Zhang P, Zam A, Jian Y, Wang X, Li Y, Lam KS, Burns ME, Sarunic MV, Pugh EN Jr, Zawadzki RJ. In vivo wide-field multispectral scanning laser ophthalmoscopy-optical coherence tomography mouse retinal imager: longitudinal imaging of ganglion cells, microglia, and Muller glia, and mapping of the mouse retinal and choroidal vasculature. J Biomed Opt. 2015;20:126005.

28. Liyanage SE, Gardner PJ, Ribeiro J, Cristante E, Sampson RD, Luhmann UF, Ali RR, Bainbridge JW. Flow cytometric analysis of inflammatory and resident myeloid populations in mouse ocular inflammatory models. Exp Eye Res. 2016;151:160-70.

29. Yu YR, O'Koren EG, Hotten DF, Kan MJ, Kopin D, Nelson ER, Que L, Gunn MD. A protocol for the comprehensive flow cytometric analysis of immune cells in normal and inflamed murine non-lymphoid tissues. PLoS One. 2016; 11:e0150606.

30. Yang J, Zhang L, Yu C, Yang XF, Wang H. Monocyte and macrophage differentiation: circulation inflammatory monocyte as biomarker for inflammatory diseases. Biomark Res. 2014;2:1.

31. Tacke F, Randolph GJ. Migratory fate and differentiation of blood monocyte subsets. Immunobiology. 2006;211:609-18.

32. Guillemin GJ, Brew BJ. Microglia, macrophages, perivascular macrophages, and pericytes: a review of function and identification. J Leukoc Biol. 2004;75: 388-97.

33. Kezic JM, McMenamin PG. The effects of CX3CR1 deficiency and irradiation on the homing of monocyte-derived cell populations in the mouse eye. PLoS One. 2013;8:e68570.

34. Lehmann U, Heuss ND, McPherson SW, Roehrich H, Gregerson DS. Dendritic cells are early responders to retinal injury. Neurobiol Dis. 2010;40:177-84.

35. Rutar M, Natoli R, Valter K, Provis JM. Early focal expression of the chemokine C $\mathrm{Cl}$ by Muller cells during exposure to damage-inducing bright continuous light. Invest Ophthalmol Vis Sci. 2011;52:2379-88.

36. Roesch K, Jadhav AP, Trimarchi JM, Stadler MB, Roska B, Sun BB, Cepko CL. The transcriptome of retinal Muller glial cells. J Comp Neurol. 2008;509:225-38.

37. Rutar M, Natoli R, Provis JM. Small interfering RNA-mediated suppression of $\mathrm{Ccl} 2$ in Muller cells attenuates microglial recruitment and photoreceptor death following retinal degeneration. J Neuroinflammation. 2012;9:221.

38. Hu Z, Zhang Y, Wang J, Mao P, Lv X, Yuan S, Huang Z, Ding Y, Xie P, Liu Q. Knockout of $\mathrm{C} c r 2$ alleviates photoreceptor cell death in rodent retina exposed to chronic blue light. Cell Death Dis. 2016;7:e2468.

39. Feng C, Wang X, Liu T, Zhang M, Xu G, Ni Y. Expression of CCL2 and its receptor in activation and migration of microglia and monocytes induced by photoreceptor apoptosis. Mol Vis. 2017;23:765-77.

40. Bringmann A, Pannicke T, Grosche J, Francke M, Wiedemann P, Skatchkov SN, Osborne NN, Reichenbach A. Muller cells in the healthy and diseased retina. Prog Retin Eye Res. 2006;25:397-424.

41. Howell GR, Soto I, Zhu X, Ryan M, Macalinao DG, Sousa GL, Caddle LB, MacNicoll KH, Barbay JM, Porciatti V, et al. Radiation treatment inhibits monocyte entry into the optic nerve head and prevents neuronal damage in a mouse model of glaucoma. J Clin Invest. 2012;122:1246-61.

42. Xu H, Dawson R, Forrester JV, Liversidge J. Identification of novel dendritic cell populations in normal mouse retina. Invest Ophthalmol Vis Sci. 2007:48:1701-10.

43. Italiani $\mathrm{P}$, Boraschi D. From monocytes to M1/M2 macrophages: phenotypical vs. functional differentiation. Front Immunol. 2014;5:514.

44. Guillonneau X, Eandi CM, Paques M, Sahel JA, Sapieha P, Sennlaub F. On phagocytes and macular degeneration. Prog Retin Eye Res. 2017;61:98-128.

45. Amit I, Winter DR, Jung S. The role of the local environment and epigenetics in shaping macrophage identity and their effect on tissue homeostasis. Nat Immunol. 2016;17:18-25.

46. Rutar M, Natoli R, Chia RX, Valter K, Provis JM. Chemokine-mediated inflammation in the degenerating retina is coordinated by Muller cells, activated microglia, and retinal pigment epithelium. J Neuroinflammation. 2015;12:8
47. Natoli R, Fernando N, Madigan M, Chu-Tan JA, Valter K, Provis J, Rutar M Microglia-derived IL-1beta promotes chemokine expression by Muller cells and RPE in focal retinal degeneration. Mol Neurodegener. 2017;12:31.

48. Labzin LI, Heneka MT, Latz E. Innate immunity and neurodegeneration. Annu Rev Med. 2018:69:437-49.

49. Sudharsan R, Beiting DP, Aguirre GD, Beltran WA. Involvement of innate immune system in late stages of inherited photoreceptor degeneration. Sci Rep. 2017;7:17897

\section{Ready to submit your research? Choose BMC and benefit from:}

- fast, convenient online submission

- thorough peer review by experienced researchers in your field

- rapid publication on acceptance

- support for research data, including large and complex data types

- gold Open Access which fosters wider collaboration and increased citations

- maximum visibility for your research: over $100 \mathrm{M}$ website views per year

At $\mathrm{BMC}$, research is always in progress.

Learn more biomedcentral.com/submissions 